\title{
Antibodies against low-density lipoprotein receptor-related protein 4 induce myasthenia gravis
}

\author{
Chengyong Shen, ${ }^{1}$ Yisheng Lu, ${ }^{1}$ Bin Zhang, ${ }^{1}$ Dwight Figueiredo, ${ }^{1}$ Jonathan Bean, ${ }^{1}$ \\ Jiung Jung, ${ }^{1}$ Haitao Wu, ${ }^{1}$ Arnab Barik, ${ }^{1}$ Dong-Min Yin, ${ }^{1}$ Wen-Cheng Xiong, ${ }^{1,2}$ and Lin Mei1,2 \\ ${ }^{1}$ Institute of Molecular Medicine and Genetics and Department of Neurology, Medical College of Georgia, \\ Georgia Regents University, Augusta, Georgia, USA. ${ }^{2}$ Charlie Norwood VA Medical Center, Augusta, Georgia, USA.
}

\begin{abstract}
Myasthenia gravis (MG) is the most common disorder affecting the neuromuscular junction (NMJ). MG is frequently caused by autoantibodies against acetylcholine receptor (AChR) and a kinase critical for NMJ formation, MuSK; however, a proportion of MG patients are double-negative for anti-AChR and anti-MuSK antibodies. Recent studies in these subjects have identified autoantibodies against low-density lipoprotein receptor-related protein 4 (LRP4), an agrin receptor also critical for NMJ formation. LRP4 autoantibodies have not previously been implicated in MG pathogenesis. Here we demonstrate that mice immunized with the extracellular domain of LRP4 generated anti-LRP4 antibodies and exhibited MG-associated symptoms, including muscle weakness, reduced compound muscle action potentials (CMAPs), and compromised neuromuscular transmission. Additionally, fragmented and distorted NMJs were evident at both the light microscopic and electron microscopic levels. We found that anti-LRP4 sera decreased cell surface LRP4 levels, inhibited agrin-induced MuSK activation and AChR clustering, and activated complements, revealing potential pathophysiological mechanisms. To further confirm the pathogenicity of LRP4 antibodies, we transferred IgGs purified from LRP4-immunized rabbits into naive mice and found that they exhibited MG-like symptoms, including reduced CMAP and impaired neuromuscular transmission. Together, these data demonstrate that LRP4 autoantibodies induce MG and that LRP4 contributes to NMJ maintenance in adulthood.
\end{abstract}

\section{Introduction}

Myasthenia gravis (MG) is the most common neuromuscular junction (NMJ) disorder, affecting 20 per 100,000 people in various populations (1-3). MG patients show characteristic fatiguing weakness of voluntary muscles, including ocular, bulbar, and limb muscles; weight loss from dysphagia; and, in severe cases, death from breathing difficulty. In a majority of patients, MG appears to stem from an autoimmune response against acetylcholine receptors (AChRs), which are critical for neurotransmission at the NMJ. Autoantibodies against AChRs can be detected in $80 \%-85 \%$ of MG patients $(4,5)$. Evidence from classic experiments indicates the anti-AChR antibodies are pathogenic (6-15). In rabbit, mouse, and rat models of experimental autoimmune MG (EAMG), antiAChR antibodies block AChR activity $(8,11)$ and may accelerate AChR internalization and degradation (7). AChR deficiency decreases amplitudes of endplate potentials (EPPs) and miniature EPPs (mEPPs), consequently reducing the safety margin of neuromuscular transmission $(9,11)$. The autoantibodies may fix complements and attract macrophages, which could mediate NMJ destruction $(5,10,16-18)$.

However, AChR antibodies are not detectable in approximately $20 \%$ of MG patients. Evidence indicates that these "seronegative" MG patients may generate autoantibodies against proteins critical for NMJ formation or maintenance. Agrin released from motor neurons binds to low-density lipoprotein receptor-related

Authorship note: Chengyong Shen, Yisheng Lu, and Bin Zhang contributed equally to this work.

Conflict of interest: The authors have declared that no conflict of interest exists. Citation for this article: J Clin Invest. 2013;123(12):5190-5202. doi:10.1172/JCI66039. protein 4 (LRP4) and activates the receptor tyrosine kinase MuSK to direct NMJ formation, including AChR concentration, in the postjunctional membrane (19-27). Approximately $40 \%-70 \%$ of seronegative patients have antibodies against MuSK (28-30). Immunization with the extracellular domain of MuSK causes MG in rodents and rabbits (31-36). Passive transfer of IgG from antiMuSK-positive MG patients causes MG in adult animals (37-41). The remaining $6 \%-12 \%$ of MG patients are double-seronegative for anti-AChR and anti-MuSK antibodies.

LRP4, a member of the low-density lipoprotein receptor (LDLR) family, contains an enormously large extracellular N-terminal region that possesses multiple EGF repeats and LDLR repeats, a transmembrane domain, and a short C-terminal region (42-45). It is a receptor of agrin critical for MuSK activation, AChR clustering, and NMJ formation $(20,21,24)$. In a working model, monomeric agrin interacts with LRP4 to form a binary complex, which promotes the synergistic formation of a tetramer crucial for agrin-induced AChR clustering (46). Considering the critical role of LRP4 in NMJ formation, its large extracellular domain, and the spatial proximity with MuSK, we proposed that LRP4 may be an autoantigen in double-seronegative patients. Indeed, LRP4 autoantibodies were detected in $2 \%-45 \%$ of double-seronegative MG patients in different ethnicities and countries of origin (47-49). These results suggest that double-seronegative MG may be an autoimmune disorder caused by antibodies against LRP4.

A critical issue is whether LRP4 autoantibodies are pathogenic. Although different autoantibodies were reported in patients with MG, not all are pathogenic. For example, anti-titin antibodies are present in many MG patients, but evidence that these antibodies directly trigger NMJ pathology is lacking (50-53). To this end, we 

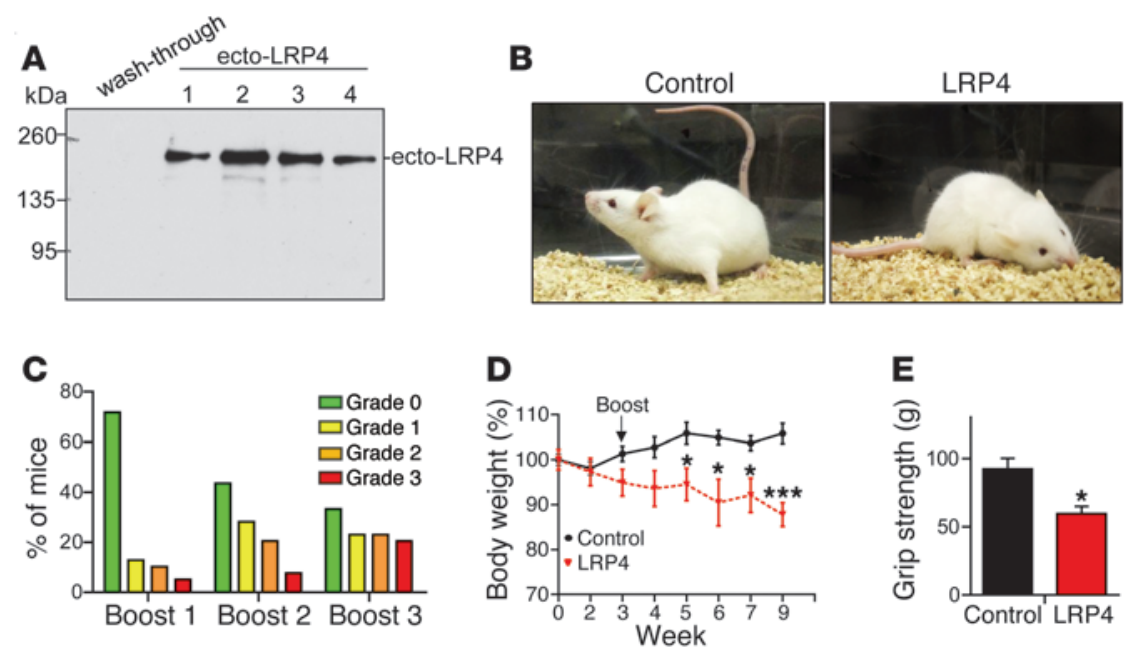

\section{Figure 1}

Immunization with LRP4 induces muscle weakness in mice. (A) Purification of ecto-LRP4. Shown are Western blot of chromatography fractions on TALON Metal Affinity resins with anti-Flag antibody. (B) Representative control and LRP4-injected A/J mice after immunization. (C) Distribution of mice with different grades of muscle weakness after each boost. (D) Reduced body weight of LRP4-injected mice with grade 2 or 3 muscle weakness. $n=8$ (control); 6 (LRP4). (E) Reduced grip strength in LRP4-injected mice with grade 3 muscle weakness after boost 3 . $n=8$ per group. ${ }^{*} P<0.05$; ${ }^{* \star *} P<0.001$. See complete unedited blots in the supplemental material. first generated EAMG models by actively immunizing mice with ecto-LRP4. Compared with controls, these mice developed clinical signs resembling those seen in MG patients and deficits in NMJ structure and function of the NMJ, which suggested that LRP4 antibodies could be pathogenic. We investigated the underlying pathophysiological mechanisms and found that LRP4 antibodies damaged the NMJ by interfering with agrin/MuSK signaling and fixing complements. To further test the pathological role of LRP4 antibodies in vivo, we purified IgG from immunized rabbits and injected it into naive mice to generate passive EAMG models. These mice exhibited MG-like symptoms, including reduced compound muscle action potentials (CMAPs) and impaired transmission, compared with those injected with $\mathrm{IgG}$ from control rabbits. These results convincingly demonstrated that LRP4 antibodies are pathogenic for MG.

\section{Results}

Immunization with LRP4 extracellular domain causes muscle weakness in mice. To determine whether anti-LRP4 antibodies were pathogenic, we generated a recombinant ecto-LRP4 that contains the entire extracellular domain (aa 21-1,723). It has a Flag tag in the N terminus (after an artificial signal peptide) and a His tag at the $\mathrm{C}$ terminus (Supplemental Figure 1A; supplemental material available online with this article; doi:10.1172/JCI66039DS1). Ecto-LRP4 was purified from lysates of transfected HEK293 cells by affinity chromatography using TALON Metal Affinity Resins. Whereas ecto-LRP4 was not detectable in wash-through, it was detected in elution fractions (Figure 1A). Silver staining confirmed that ecto-LRP4 was the major protein in the purified preparation (Supplemental Figure 1B).

Ecto-LRP4 was emulsified with CFA and injected into female $\mathrm{A} / \mathrm{J}$ mice, a strain that has been used successfully to establish

\section{Table 1}

Muscle weakness in LRP4-injected A/J mice

\begin{tabular}{cccccccc} 
& $\boldsymbol{n}$ & Grade 0 & Grade 1 & Grade 2 & Grade 3 & Total MG & Average grade \\
Control & 10 & $10(100 \%)$ & $0(0 \%)$ & $0(0 \%)$ & $0(0 \%)$ & $0(0 \%)$ & 0 \\
Boost 1 & 39 & $28(71.8 \%)$ & $5(12.8 \%)$ & $4(10.3 \%)$ & $2(5.1 \%)$ & $11(28.2 \%)$ & 0.49 \\
Boost 2 & 39 & $17(43.6 \%)$ & $11(28.2 \%)$ & $8(20.5 \%)$ & $3(7.7 \%)$ & $22(56.4 \%)$ & 0.92 \\
Boost 3 & 39 & $13(33.3 \%)$ & $9(23.1 \%)$ & $9(23.1 \%)$ & $8(20.5 \%)$ & $26(66.7 \%)$ & 1.31 \\
\hline
\end{tabular}

MuSK EAMG $(33,36)$. Mice received 3 boost injections (at weeks 4, 7, and 16) with ecto-LRP4 emulsified with incomplete Freund adjuvant (IFA); control mice were injected with emulsified PBS. No muscle weakness was observed in control mice throughout the entire experiment. However, after boost 1, LRP4-injected mice started to show signs of muscle weakness, including chin down, flaccid tail, and unwillingness to move when handled (Figure $1 \mathrm{~B}$ ). When severity of muscle weakness was determined (54), $71.8 \%$ of mice we scored as grade 0 (no apparent muscle weakness) after boost 1 , and $5.1 \%$ exhibited grade 3 weakness, characterized by severe flaccid weakness, kyphosis, and weight loss (Figure 1C). With subsequent boosts, mice with muscle weakness increased in frequency, and those without weakness decreased. After boost 3, $66.7 \%$ of mice showed muscle weakness: $23.1 \%$ were grade 1 (mild fatigue after exercise), 23.1\% were grade 2 (markedly decreased activity, hunched posture at rest without exercise), and $20.5 \%$ were grade 3 (Table 1 ). These results were indicative of progressive muscle weakness in LRP4-injected mice. After boost 1 , mice with grade 2 and grade 3 muscle weakness started to show significant body weight loss (Figure 1D), probably due to difficulty in chewing and ingesting food caused by muscle weakness. To determine whether muscle strength was indeed reduced, we measured limb grip strength and found it to be significantly lower in LRP4-injected versus control mice (Figure 1E). We subsequently used LRP4-injected mice with grade 3 muscle weakness for our experiments, unless otherwise indicated.

Detection and characterization of LRP4 antibodies in immunized mice. To examine whether LRP4 immunization induced LRP4 antibodies, blood of control and LRP4-injected mice was collected via orbital sinus. The resulting sera were tested by ELISA, following a protocol previously used by our laboratory to detect LRP4 autoantibodies in MG patients (48). ELISA OD readings of LRP4-injected mouse sera were significantly higher than those of control sera (control, $0.027 \pm 0.009, n=10$; boost 1 , $0.673 \pm 0.059, n=39$; boost $2,0.710$ $\pm 0.066, n=30$; boost $3,0.583 \pm$ $0.048, n=30 ; P<0.001$; Figure 2A), which indicates that LRP4-immunized mice generate antibodies 


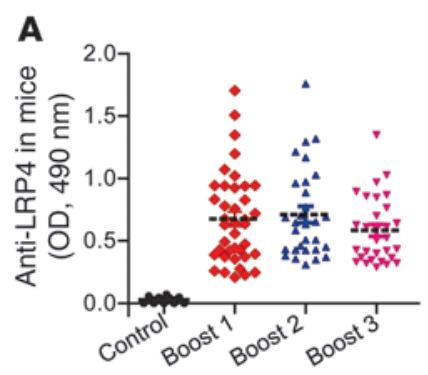

B

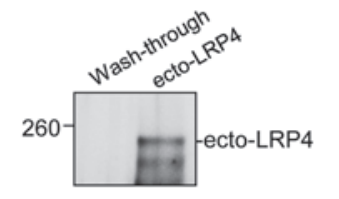

E

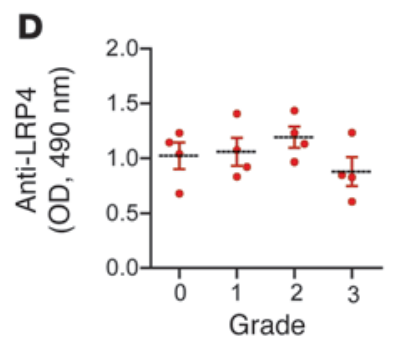

C
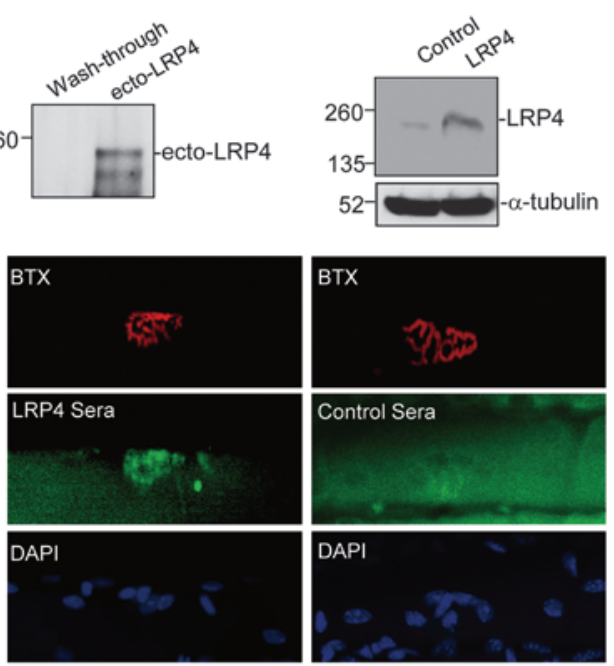

DAPI
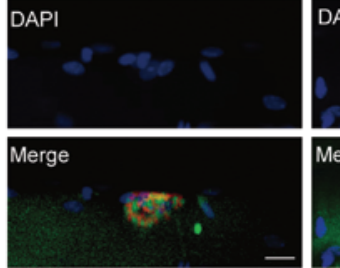

Figure 2

Characterization of anti-LRP4 antibodies in LRP4injected mice. (A) Detection of anti-LRP4 antibodies in sera of injected mice, which were collected after each boost and subjected to ELISA. $n=10$ (control); 39 (boost 1); 30 (boosts 2 and 3 ). $P<0.001$ vs. control. (B and C) Ability of mouse anti-LRP4 antibodies to recognize LRP4. Purified ecto-LRP4 (B) and lysates of cells transfected with LRP4 or empty vector control (C) were subjected to Western blot with sera from LRP4-injected mice. $\alpha$-tubulin blot indicates equal loading. (D) No apparent correlation between anti-LRP4 antibody titer and muscle weakness. The $y$ axis shows half maximum of LRP4 antibody titer, revealed by ELISA, of serial dilutions of EAMG sera. (E) NMJ staining with antiLRP4 antibody. Normal muscle fibers were stained with sera from control or LRP4-injected mice, and immunoreactivity was visualized by Alexa Fluor 488-conjugated goat anti-mouse antibody. AChR and nuclei were stained by R-BTX and DAPI, respectively. Scale bars: $20 \mu \mathrm{m}$. See complete unedited blots in the supplemental material. against LRP4. The antibodies recognized purified ecto-LRP4 (Figure $2 \mathrm{~B})$. To determine whether they recognize full-length LRP4, lysates of HEK293 cells transfected with or without LRP4 were resolved by SDS-PAGE and subjected to Western blot analysis. LRP4-injected mouse serum was able to detect full-length LRP4 protein around $250 \mathrm{kDa}$ (Figure 2C). There was no apparent correlation between anti-LRP4 titer (half-maximum) and muscle weakness after boost 3 (Figure 2D), which may suggest heterogeneity of specificities of anti-LRP4 antibodies in the LRP4-injected mice. Such poor correlation has been previously observed in AChR EAMG and in MG patients with antibodies against $\operatorname{AChR}(5,55,56)$.

Next, we determined whether LRP4 antibodies from immunized mice interact with endogenous LRP4 at the NMJ. Gastrocnemius muscles were subjected to whole-mount staining with a mixture of anti-LRP4 sera and rhodamine-conjugated $\alpha$-bungarotoxin (R-BTX) to label AChR (57). AChR clusters exhibited characteristic pretzel-like morphology, with complex continuous branches. Staining with anti-LRP4 sera, but not sera from control mice, colocalized with R-BTX (Figure 2E), which suggests that anti-LRP4 antibodies were able to recognize endogenous LRP4 at the NMJ. To examine whether anti-LRP4 sera contained antibodies against AChR to cause MG, HEK293 cells were transfected with the AChR $\alpha$ subunit, a major antigen in MG patients $(58,59)$. Expression of the $\alpha$ subunit was evident by Western blot with mAb35 (Supplemental Figure 2), a rat monoclonal antibody (57). Blotting with anti-LRP4 sera failed to detect the AChR $\alpha$ subunit. These results suggest that sera from LRP4-immunized mice did not contain antibodies against the AChR $\alpha$ subunit, excluding the possibility that weakness of LRP4-injected mice was caused by anti-AChR. These observations indicate that anti-LRP4 antibodies of immunized mice are able to recognize LRP4 in transfected cells and at the NMJ in vivo.

LRP4 immunization impairs neuromuscular transmission. To investigate pathophysiological mechanisms of muscle weakness in LRP4-immunized mice, we sought to determine whether neuromuscular transmission is impaired. CMAPs were measured in gas- trocnemius muscle in response to repetitive nerve stimuli (40). In control mice, CMAPs showed little or no change after 10 consecutive nerve stimuli at frequencies from $2 \mathrm{~Hz}$ to $40 \mathrm{~Hz}$ (Figure 3). In contrast, CMAPs in LRP4-immunized mice stimulated at $20 \mathrm{~Hz}$ began to decrease at the second stimulus and significantly decreased from the fourth; the decrement of CMAP at the tenth stimulus was about $10 \%$ (Figure 3C). When the frequency was increased to $40 \mathrm{~Hz}$, CMAP reduction was observed as early as the second stimulus, and the decrement of CMAP at the tenth stimulus was about $30 \%$ (Figure 3D). Even at $10 \mathrm{~Hz}$, the CMAP amplitudes after the tenth stimulus were significantly smaller than those of control mice (Figure 3E). Importantly, the reduction of CMAPs in LRP4-injected mice was frequency dependent (Figure 3E), which indicates progressive loss of successful neuromuscular transmission after repeated stimulation. These observations provide pathophysiological mechanisms of fatigable muscle weakness in LRP4-injected mice.

To investigate whether the neurotransmission deficits result from pre- and/or postsynaptic impairment, we first measured mEPPs, events generated by spontaneous vesicle release. Electrophysiological recordings at diaphragm NMJs revealed that $\mathrm{mEPP}$ amplitudes were reduced by $20 \%$ compared with controls $(0.805 \pm 0.037$ vs. $1.01 \pm 0.047 \mathrm{mV} ; n=8 \mathrm{each} ; P<0.05$; Figure $4, \mathrm{~A}, \mathrm{~B}$, and D). These results were suggestive of reduced AChR density at the postjunctional membrane and/or reduced ACh concentration in individual synaptic vesicles in LRP4-injected mice. On the other hand, mEPP frequencies also decreased by approximately $40 \%$ in LRP4-injected versus control mice $(0.997 \pm 0.044$ vs. $1.72 \pm 0.061 \mathrm{~Hz} ; n=8$ each; $P<0.05$; Figure 4, A, C, and E), which suggests potential deficits in spontaneous ACh release. Next, we compared EPPs, an indicator of evoked neurotransmission, between control and LRP4-immunized mice. EPP amplitudes in LRP4-injected mice were smaller than those in control mice $(11.5 \pm 1.0$ vs. $19.5 \pm 0.4 \mathrm{mV} ; n=5$ each; $P<0.05$; Figure 4F). EPP quantum content - determined as the ratio of EPP amplitude to $\mathrm{mEPP}$ amplitude - was also decreased, from $19.3 \pm 0.4$ in control mice to $14.3 \pm 1.2$ in LRP4-injected mice 
A

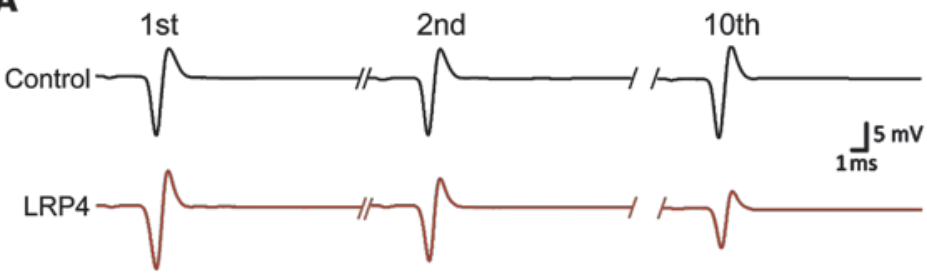

B
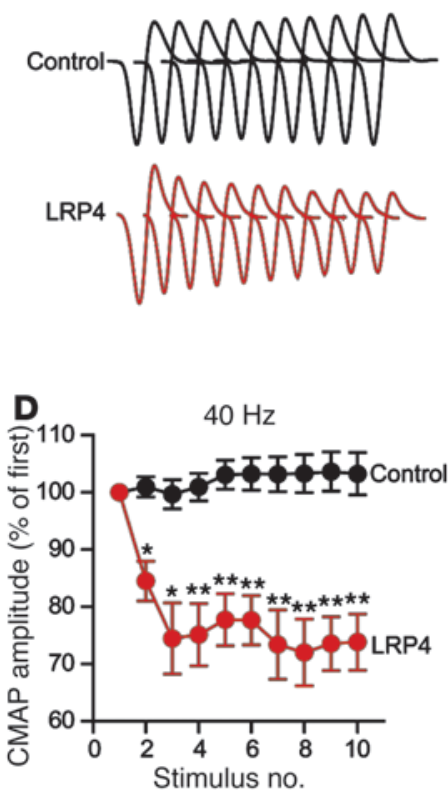

c

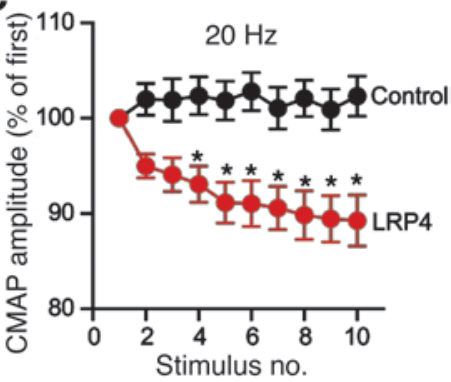

E

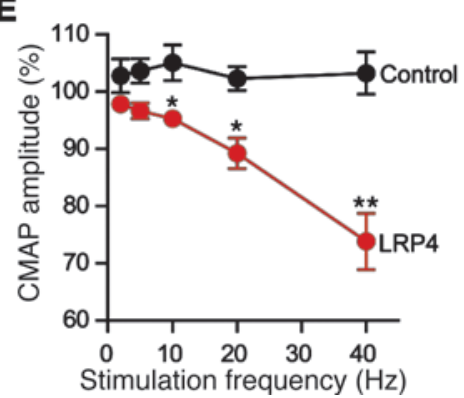

\section{Figure 3}

CMAP reduction in LRP4-injected mice. CMAPs were recorded in gastrocnemius in response to a train of 10 submaximal stimuli at different frequencies. The first stimulus response in control mice was designated as $100 \%$. (A) Representative CMAP traces of control and LRP4-injected mice. Shown are traces in response to the first, second, and tenth stimuli. (B) All 10 CMAP traces, shown stacked in succession for better comparison. (C and D) Reduced CMAP amplitudes at $20 \mathrm{~Hz}$ (C) or $40 \mathrm{~Hz}$ (D). (E) CMAP amplitudes of the tenth stimulation at different stimulation frequencies. $n=8$ per group. ${ }^{*} P<0.05 ;{ }^{* \star} P<0.01$.
$(P<0.05)$. These results indicated deficits of evoked vesicle release. To further determine whether vesicle release probability was altered in injected mice, we examined paired-pulse facilitation (PPF) at different interstimulus intervals (Figure 4G). Under normal conditions, EPP caused by the second pulse is higher because the first pulse increases terminal calcium concentration. At 10-ms intervals, PPF was higher at NMJs from LRP4-injected than control mice, suggesting reduced release probability of synaptic vesicles. The difference was reduced at increased intervals and diminished at 100 -ms intervals, suggestive of normal calcium buffering by endoplasmic reticulum at NMJs of LRP4-injected mice. These electrophysiological results were indicative of compromised probability of calcium-dependent vesicle release. Taken together, our findings are suggestive of both pre- and postsynaptic deficits in neuromuscular transmission in LRP4-injected mice.

LRP4 is a protein expressed in various tissues, including skeletal muscles and motor nerve terminals $(24,45,57,60)$. LRP4 in motor neurons may serve as an antigen, and the resulting immune reaction may damage the structure and function of motor nerve terminals. To test this hypothesis, HB9-Cre;LRP4f/f and HB9-Cre;LRP4+/+ mice (the latter serving as a control) were injected with emulsified ecto-LRP4 or adjuvant alone (see Methods). Immunization of both genotypes significantly reduced body weight $(\sim 7 \%-8 \%)$ and muscle strength ( $25 \%-30 \%)$; however, no difference was observed between genotypes (Supplemental Figure 3, A and B). Immunization of both genotypes reduced CMAPs at different frequencies as well as mEPP amplitudes and frequencies compared with the respective nonimmunized controls (Supplemental Figure 3, C-H). However, there was no difference in CMAPs and mEPP amplitudes and frequencies between the 2 genotypes. These results suggest that NMJ structural and functional damages in active EAMG models were likely mediated by LRP4 in muscle fibers. Presynaptic deficits in LRP4-immunized mice may be secondary to postsynaptic deficits, in mechanisms similar to those implicated in synaptic deconstruction during synapse elimination (61).

Fragmented and poorly innervated NMJs in LRP4-injected mice. To determine whether LRP4 immunization causes NMJ structural changes, whole-mount gastrocnemius was stained with a mixture of R-BTX, to label AChR, and antibodies against neurofilament (NF) and SV2, to label nerve branches and terminals. Subsequently, $z$-serial images were collected with a Zeiss confocal microscope and collapsed into single images. In control mice, NMJs exhibited characteristic pretzel-like morphology, with complex continuous branches (Figure 5, A and B). In contrast, NMJs of LRP4-injected mice were no longer pretzel-like, but fragmented, with reduced complexity of branches. AChR clusters were small and isolated (Figure 5, A and B). To ensure that these morphology deficits were not due to variations in viewing angles, NMJs were imaged from additional axes. Only the largest images of AChR clusters were subjected to analysis and quantification. The number of fragmented AChR clusters was increased about 3-fold in LRP4-injected versus control mice ( $4.10 \pm 0.66$ vs. $1.20 \pm 0.13 ; P<0.001$; Figure $5 \mathrm{C})$. The total area of R-BTX staining per NMJ was reduced in LRP4-injected mice compared with controls $\left(332 \pm 41.9\right.$ vs. $749 \pm 73.7 \mu \mathrm{m}^{2}$; 
$P<0.001$; Figure 5D). Moreover, AChR intensity was decreased by $66 \%$ in LRP4-injected mice $(P<0.01$; Figure $5 \mathrm{E})$, in agreement with the diminished mEPP amplitudes observed (Figure 4). In control mice, nerve fibers were continuous, as evidenced by NF/SV2 staining, and terminal signal colocalized well with postsynaptic AChR pattern; in contrast, nerve fibers in LRP4-injected mice appeared to be fragmented and disorganized. The total AChR area covered by axon terminals was reduced from $94.0 \% \pm 1.3 \%$ in control mice to $48.8 \% \pm 6.1 \%$ in LRP4-injected mice $(P<0.01$; Figure $5 \mathrm{~F})$, in agreement with the reduced $\mathrm{mEPP}$ frequency demonstrated by electrophysiological recordings (Figure 4).

Next, we performed electron microscopic analysis to investigate NMJ ultrastructural changes in LRP4-injected mice. As in control mice, axon terminals in LRP4-injected mice were wrapped by processes of terminal Schwann cells (Figure 6A). Junctional folds in LRP4-injected mice appeared to be fewer than - and not as deep as - those in controls (Figure 6, A and B), in agreement with the simplified NMJs revealed by light microscopy (Figure 5). Moreover, there were fewer synaptic vesicles at NMJs of LRP4-injected versus control mice ( $41.3 \pm 4.4$ vs. $103 \pm 14$ per $\mathrm{mm}^{2}$; $P<0.01$; Figure 6, $A$ and $C)$. This may elucidate a cellular mechanism of mEPP frequency reduction. However, there was no change in vesicle diameter between control and injected mice (Figure 6D). Taken together, these observations demonstrated NMJ ultrastructural impairment in LRP4-injected mice, in agreement with our light microscopic and electrophysiological observations. These results suggest that LRP4 function may be critical for NMJ maintenance.

Inbibition of agrin-induced AChR clustering by LRP4 autoantibodies. We investigated molecular mechanisms by which LRP4 antibodies may perturb NMJ stability. Agrin binds to LRP4 to activate MuSK and thus stimulates AChR clustering in muscle cells, an event thought to be critical for high AChR concentration at the NMJ $(20,21)$. Indeed, MuSK is necessary for NMJ stability $(62,63)$. Having demonstrated that LRP4 antibodies bound to LRP4 (Figure 2), we next sought to determine whether they impair agrin-induced AChR clustering. AChR clusters increased in C2C12 myotubes in response to agrin treatment (Figure $7 \mathrm{~A})$. Treatment with control serum had no effect on agrin-induced AChR clustering (Figure 7, A and B). Conversely, agrin-induced AChR clustering was inhibited by sera from LRP4-injected mice. We also examined effects of LRP4 antibodies on spontaneous AChR cluster formation (i.e., without agrin stimulation). There was no apparent difference between sera from control and LRP4-injected mice (Figure 7, A and B). These results demonstrate that LRP4 antibodies could inhibit agrininduced AChR clustering.

To investigate the underlying mechanisms, we sought to determine whether LRP4 antibodies block agrin-induced MuSK activation. C2C12 myotubes were pretreated with agrin, and MuSK was isolated by immunoprecipitation and probed with the antiphospho-tyrosine antibody 4G10. Agrin elicited MuSK phosphorylation in C2C12 myotubes (Figure 7C). Sera from control mice had little effect on agrin-induced MuSK activation. In contrast, agrininduced phospho-MuSK was diminished in C2C12 myotubes treated with sera from LRP4-injected mice (Figure 7, C and D). Notably, MuSK total protein levels remained consistent in the presence or absence of sera from control or LRP4-injected mice (Figure 7C). These observations indicate that sera from LRP4injected mice could prevent agrin from activating MuSK. With binding to LRP4, the antibodies may decrease cell surface LRP4 by cross-linking-induced internalization. Biotin-labeled cell surface
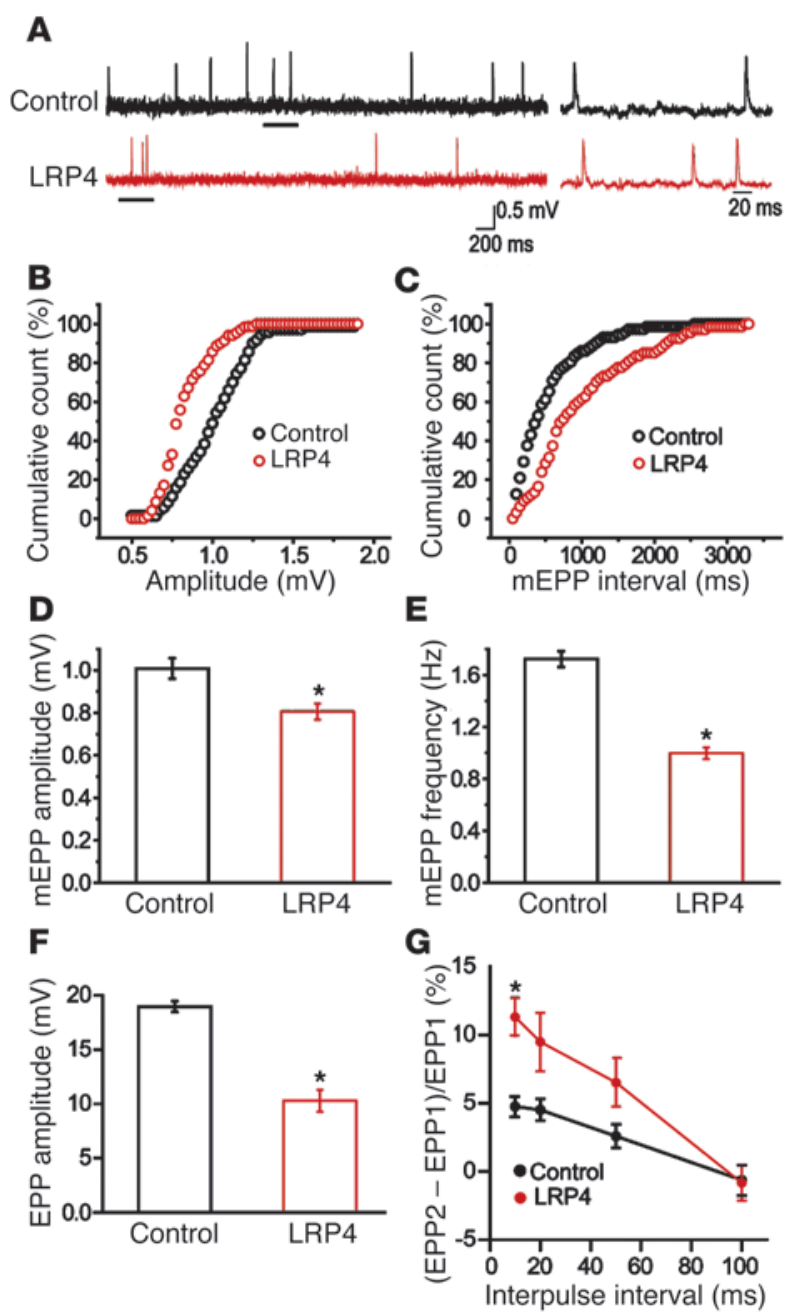

\section{Figure 4}

Impaired neuromuscular transmission in LRP4-injected mice. (A) Representative mEPP traces. Traces at right are enlargements of underlined regions at left. (B and $\mathbf{C}$ ) Cumulative plots of mEPP events against amplitude (B) or interval (C). ( $\mathbf{D}$ and $\mathbf{E})$ Reduced mEPP amplitude (D) and frequency (E) in LRP4-injected mice. $n=8$ per group. (F) Reduced EPP amplitude in LRP4-injected mice. $n=5$ per group. (G) Increased PPF in LRP4-injected mice. $n=5$ per group (3-4 muscle fibers per mouse). ${ }^{*} P<0.05$.

LRP4 was reduced in C2C12 myotubes treated with LRP4 antibodies versus controls (Figure 7, E and F).

Complement fixation by LRP4 antibodies. To determine whether complement-mediated cell lysis serves as a mechanism of LRP4 antibodies in damaging NMJs, we first performed isotyping analysis of LPR 4 antibodies of injected mice. The dominant subclass of LRP4 antibodies was IgG1 (44.9\% $\pm 2.9 \%)$, followed by $\operatorname{IgG} 2 \mathrm{a}$ and $\operatorname{IgG} 2 \mathrm{~b}(17.4 \% \pm 2.2 \%$ and $22.3 \% \pm 2.8 \%$, respectively), and then $\operatorname{IgG} 3$ and $\operatorname{IgM}(5.5 \% \pm 1.0 \%$ and $9.8 \% \pm$ $1.3 \%$, respectively; Figure $8 \mathrm{~A}$ ). IgA was undetectable (data not shown). Given that mouse IgG2a, IgG2b, and IgG3 have previously been implicated in complement activation $(64,65)$, we next sought to determine whether anti-LRP4 sera are able to fix complement. C2C12 myotubes were incubated first with control 
A

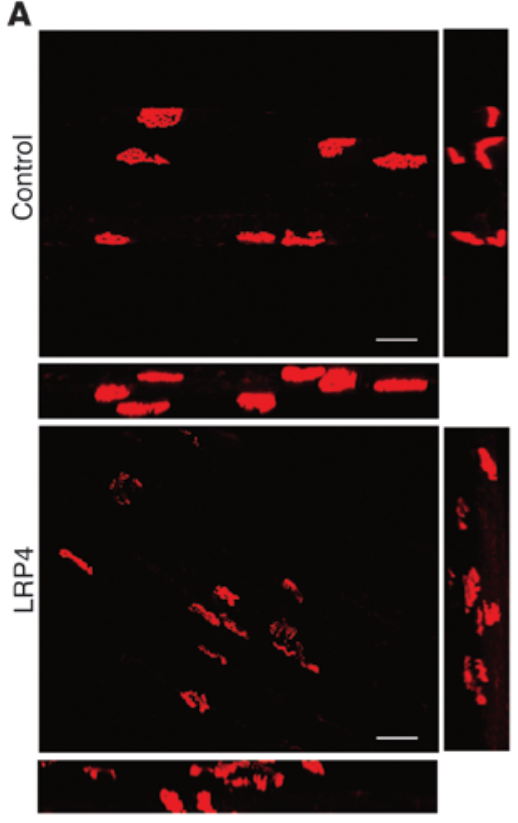

B
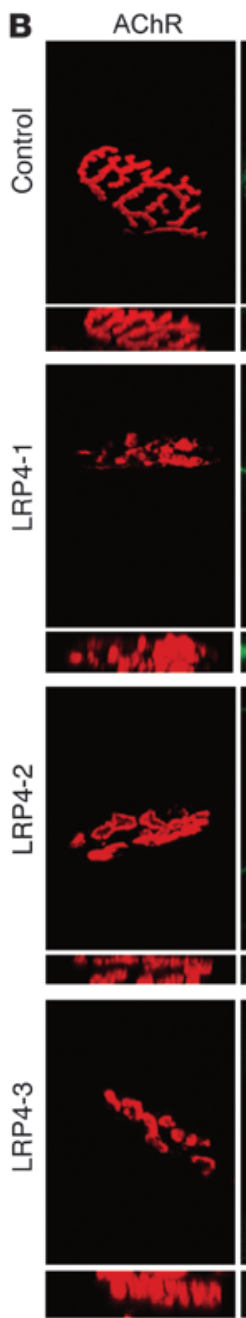

NF/SV2
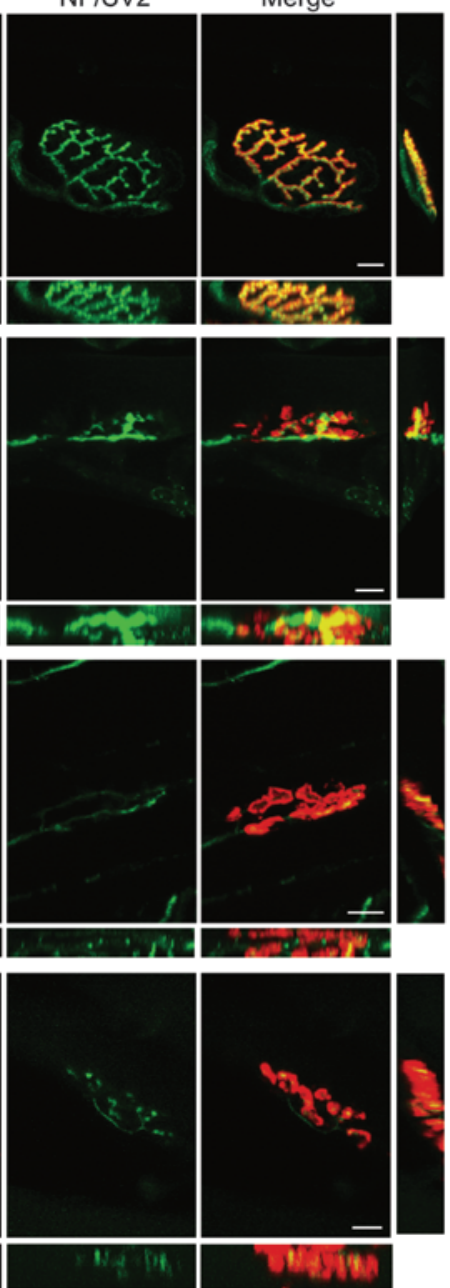

Merge

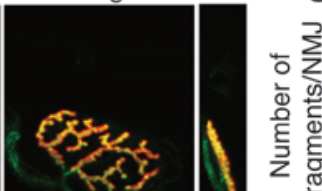

C

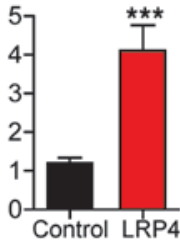

D

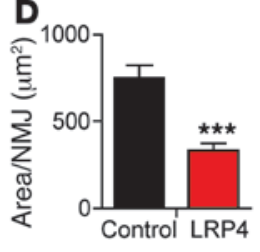

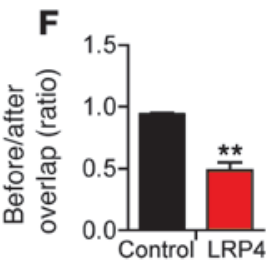

\section{Figure 5}

Fragmented AChR clusters and distorted axon terminals in LRP4-injected mice. Gastrocnemius was stained whole-mount with R-BTX (red) to label AChR and antibodies against NF and SV2 (NF/SV2; green) to label nerve branches and terminals. (A and B) Collapsed z-stack images of NMJs from control and LRP4-injected mice. Lateral and top views of the reconstructed 3D images are shown at right and bottom, respectively. Scale bars: $50 \mu \mathrm{m}(\mathbf{A}) ; 10 \mu \mathrm{m}$ (B). (C-F) Quantitative analysis of data by Image J. $n=3$ per group. (C) Increased fragments of AChR clusters. (D) Reduced AChR area per NMJ. (E) Decreased AChR intensity. (F) Reduced overlap area of NF/SV2 and AChR staining. ${ }^{* \star} P<0.01 ;{ }^{* \star *} P<0.001$.

or anti-LRP4 sera and then with guinea pig complement, and antibody-mediated cytotoxicity was measured using lactate dehydrogenase (LDH) release assay (66). Compared with C2C12 myotubes treated with control sera, there was a $2.3 \pm 0.1$-fold increase in complement-mediated cell lysis of cells treated with anti-LRP4 sera $(P<0.05$; Figure 8B). This effect was mediated by LRP4 on C2C12 surface, because it was not previously observed in C2C12 myoblasts that do not express LRP4 (21). As anti-LRP4 bound to NMJ in vivo (Figure 2), these results suggest that LRP4 antibodies may damage NMJs by activating complements at the NMJ.

Transfer of LRP4 antibodies caused muscle weakness and damaged NMJs. To conclusively prove that LRP4 antibodies are pathogenic, we performed passive EAMG experiments. Because serum production in mice is limited, we immunized rabbits with ecto-LRP4. LRP4 antibodies were detected in ecto-LRP4-immunized, but not control, rabbits (Supplemental Figure 4A). During the period of
3 boosts, 2 of the 3 immunized rabbits showed apparent muscle weakness and decreased activity and lost body weight by $10 \%$, in contrast to $10 \%$ weight gain in control rabbits (Supplemental Figure 4, B and C). IgG was purified from these 2 LRP4-immunized rabbits and control rabbits by ammonium sulfate precipitation and chromatography on a Sephacryl S-200 column (Supplemental Figure 5A), following an established protocol (67). Purified IgGs migrated as $150 \mathrm{kDa}$ on nondenaturing PAGE (Supplemental Figure 5B), but as 2 bands at 50 and $25 \mathrm{kDa}$, which correspond with IgG heavy and light chain, respectively (Supplemental Figure 5C). These results demonstrated that purified IgGs existed mainly as dimers under native conditions.

To generate passive EAMG models, B6/D2 F1 mice, which were previously used successfully as a passive immunization model for AChR antibody (68), were injected with rabbit IgG daily for 24 days $(10 \mathrm{mg} / \mathrm{d}$ i.p.). Mice injected with control rabbit IgGs showed no 

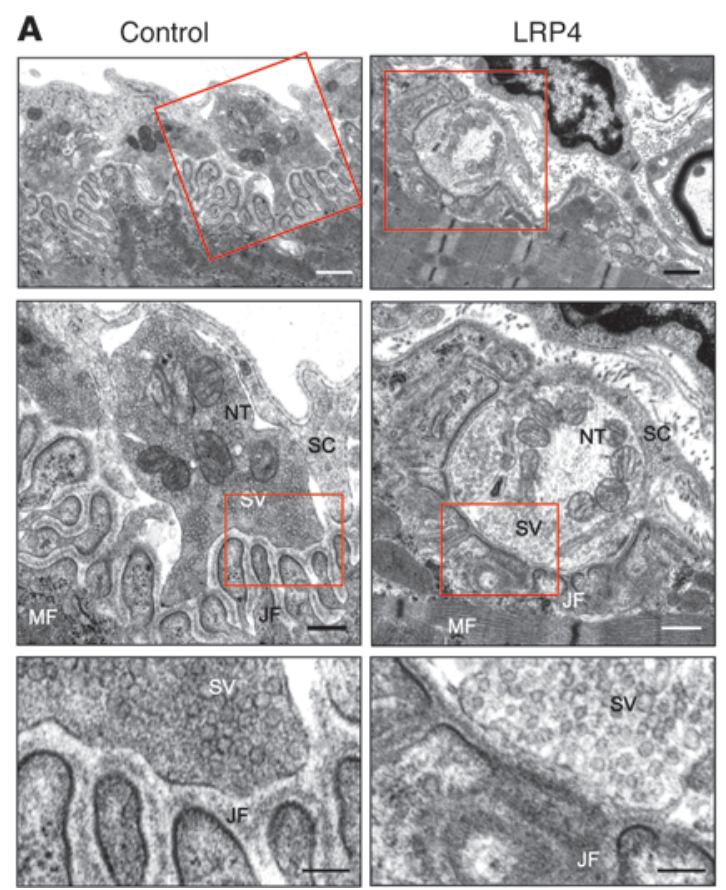

B
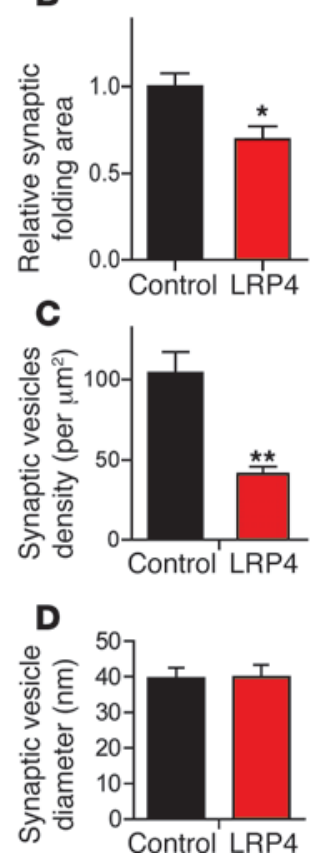

\section{Figure 6}

Abnormal NMJ ultrastructure in LRP4-injected mice. (A) Representative electron microscopic images of diaphragm NMJs of control and LRP4-injected mice. Boxed regions are shown at higher magnification immediately below. NT, nerve terminal; MF, muscle fiber; SC, Schwann cell; SV, synaptic vesicles; JF, junctional folds. Scale bars: $1.0 \mu \mathrm{m}$ (top); $0.5 \mu \mathrm{m}$ (middle); $0.2 \mu \mathrm{m}$ (bottom). (B) Reduced synaptic folding area at NMJs in sections from LRP4-injected mice. (C) Reduced synaptic vesicle density at NMJs in sections from LRP4-injected mice. (D) No change in synaptic vesicle diameter between control and LRP4-injected sections. $n=15$ (control); 21 (LRP4). ${ }^{*} P<0.05 ;{ }^{* *} P<0.01$. muscle weakness; in contrast, all 4 B6/D2 F1 mice injected with rabbit anti-LRP4 antibodies showed markedly decreased activity and hunched posture after exercise (Figure 9A). Their body weight decreased to $88.4 \% \pm 1.8 \%$ and muscle strength to $57.4 \% \pm 6.2 \%$ that of control IgG-injected mice $(P<0.05$ for each; Figure 9, $\mathrm{B}$ and $\mathrm{C})$. CMAPs were not altered in mice injected with control IgG. However, B6/D2 F1 mice injected with rabbit anti-LRP4 antibodies exhibited CMAP reduction similar to that observed in active EAMG mice (Figure 3). In particular, CMAP reduction was more severe after repetitive nerve stimulation, in a frequencydependent manner (Figure 9, D-G). These results demonstrated that neurotransmission in passive EAMG mice was not sustainable after repeated stimulations. Finally, NMJs of these mice were fragmented and less complex compared with controls (Figure 9, $\mathrm{H}-\mathrm{J}$ ). The number of fragmented AChR clusters was increased in LRP4 IgG-injected mice (control, $1.75 \pm 0.25$; LRP4, $3.75 \pm 0.75$; $P<0.05$; Figure 9I), whereas the total area of R-BTX staining per NMJ was reduced to $48 \%$ of the control $(P<0.05$; Figure $9 \mathrm{~J})$. Taken together, these results demonstrated that passive transfer of antiLRP4 antibodies could damage NMJ structures and was sufficient to induce weakness in naive mice.

\section{Discussion}

LRP4 autoantibodies have been identified in sera of doubleseronegative MG patients that lack antibodies against AChR and MuSK (47-49). However, whether LRP4 autoantibodies are pathogenic and truly able to alter NMJ structure and/or function remains unclear. Here we provided evidence that LRP4 antibodies are pathogenic and induce MG-like deficits. First, mice immunized with ecto-LRP4 generated antibodies against LRP4 and exhibited signs of muscle weakness in concert with fatigue and weight loss. CMAPs were reduced in response to repetitive nerve stimulations in LRP4-injected mice. NMJs became fragmented, disorganized, and poorly innervated in LRP4-injected mice. Second, our electrophysiological and morphological studies revealed cellular mechanisms. For example, on the postjunctional side, AChR density was reduced and junctional folds were diminished. Presynaptically, synaptic vesicle density was decreased, and ACh release was compromised. Third, LRP4 antibodies inhibited agrin-induced MuSK activation and AChR clustering in muscle cells and mediated complement-dependent cell lysis, identifying potential underlying pathological mechanisms. Finally, transfer of anti-LRP4 IgG from immunized rabbits into naive mice caused MG-like symptoms, including reduced CMAPs and impaired transmission, in the recipients. Together, these observations demonstrated that LRP4 autoantibodies are pathogenic in causing MG, uncovered underlying pathological mechanisms, and revealed an essential role of LRP4 in NMJ maintenance in adulthood.

MG is an autoimmune disorder in which patients may generate antibodies against various proteins. In the majority of MG patients, the disorder appears to result from an autoimmune response against muscle nicotinic $\operatorname{AChR}(4,5)$; for some, the disorder is due to antibodies against $\operatorname{MuSK}(28,29)$. The pathogenic mechanisms of AChR and MuSK antibodies have been studied extensively. For example, AChR autoantibodies may accelerate internalization and degradation of AChRs or functionally block the ACh binding site on the $\operatorname{AChR}(7-9,11)$. As a result, neuromuscular transmission is impaired $(5,11,12)$. In active MuSK EAMG models, immunization with the extracellular domain of MuSK causes flaccid weakness, reduces CMAPs, and decreases size and density of AChR clusters at the NMJs in rodents and rabbits (31-36). Passive transfer of IgGs from anti-MuSK-positive MG patients also induces similar MGlike phenomena (37-41). MuSK autoantibodies are able to attenuate agrin-induced MuSK activation and clustering in muscle cells $(28,31,33,36)$. They can also induce MuSK dimerization, thus activating the kinase in the absence of agrin $(31,36,69)$ and increasing basal AChR clustering (28). 
A
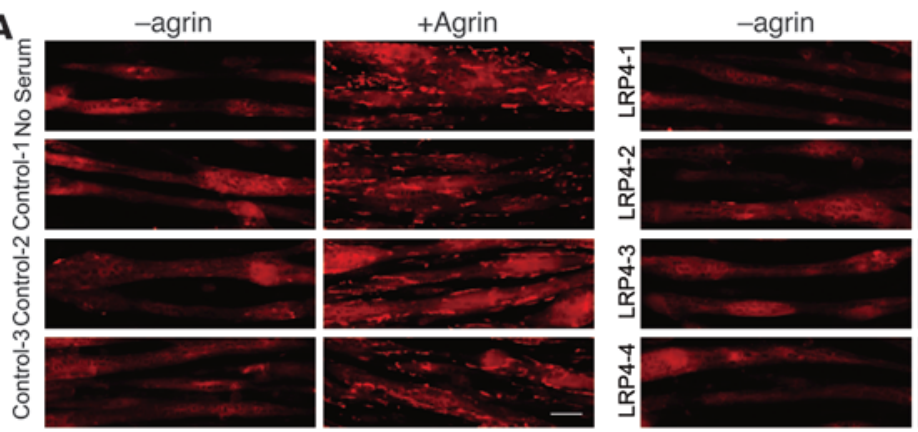

C

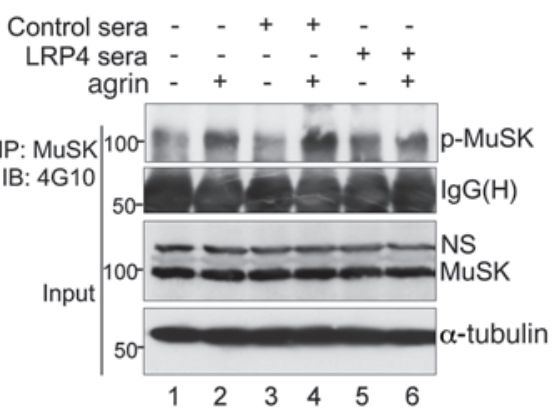

$\mathbf{F}$
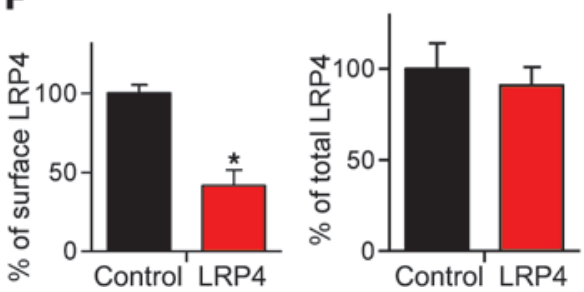

D
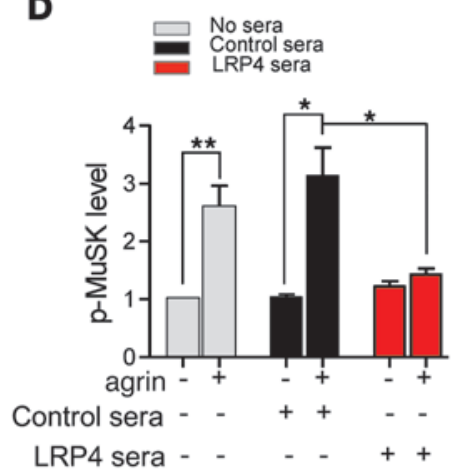

LRP4 sera - - - - + +
+Agrin

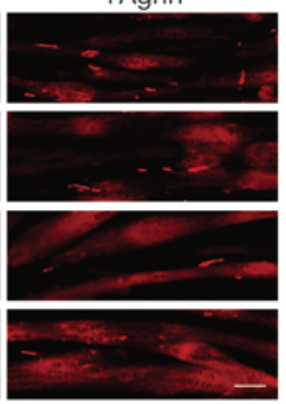

B

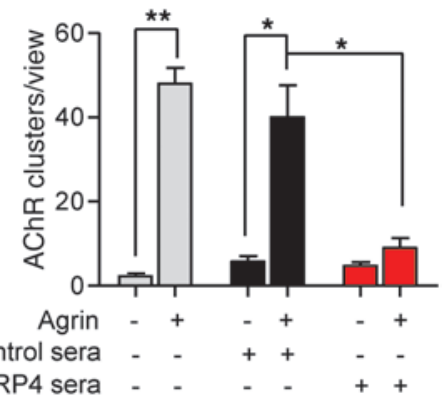

E

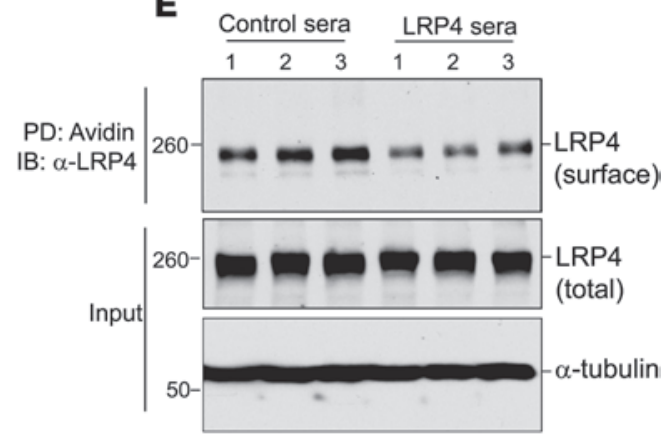

Figure 7

Inhibition of agrin signaling and AChR clustering by anti-LRP4 sera. (A) C2C12 myotubes were stimulated for 16 hours with or without agrin in the presence of sera from control or LRP4-injected mice. AChR clusters were visualized by R-BTX staining. Scale bars: $50 \mu \mathrm{m}$. (B) Quantification of AChR clusters $>4 \mu \mathrm{m}$ in length from $\mathbf{A}$. (C) C2C12 myotubes were pretreated with sera from control or LRP4-injected mice for 3 hours prior to incubation with agrin for 30 minutes. MuSK was isolated by immunoprecipitation with anti-MuSK antibody and probed with $4 \mathrm{G} 10$ to reveal phospho-MuSK. Lysates were also probed directly with antibodies against MuSK and $\alpha$-tubulin as input control. (D) Quantitative analysis of data in C. (E) Reduced surface LRP4 in sera-treated C2C12 myotubes. Cells were treated with sera from control or LRP4-injected mice for 1 hour. Surface protein was labeled by biotin, isolated by avidin beads, and probed with anti-ecto-LRP4 to reveal cell surface LRP4. Lysates were also probed to reveal total LRP4. (F) Quantitative analysis of data in E (3 independent experiments). ${ }^{*} P<0.05$; ${ }^{* *} P<0.01$. See complete unedited blots in the supplemental material.

Sera from double-seronegative MG patients and from LRP4injected mice were able to interact with LRP4 on cell membranes and/or recognize NMJ in vivo (Figure 2 and refs. 47-49) and also inhibited agrin-induced AChR clustering (Figure 7 and refs. 47, 48). LRP4 antibodies did not appear to affect basal MuSK activity or AChR clustering (Figure 7), which suggests that they may be unable to induce MuSK dimerization. However, LRP4 antibodies from LRP4-immunized mice inhibited agrin-induced activation of MuSK (Figure 7). The binding site for agrin is the first $\beta$-propeller domain, whereas the motifs for MuSK interaction are the fourth and fifth LDL $\alpha$ domains and the third $\beta$-propeller domain $(25,70)$. Agrin-LRP4 or LRP4-MuSK interactions can be disrupted by autoantibodies that may interact directly with these sites or indirectly with a remote site to change the extracellular domain's conformation. Indeed, LRP4 autoantibodies were previously shown to disrupt the interaction between LRP4 and agrin $(48,49)$.
Here, we identified 2 novel pathological mechanisms of LRP4 antibodies. First, they mediated LRP4 endocytosis and reduced surface expression, thus diminishing agrin signaling (Figure 7). Second, LRP4 antibodies contained IgG isotypes able to activate complements and mediate complement-dependent cell lysis (Figure 8). Therefore, the pathological mechanisms of LRP4 antibodies are likely complex and involve not only disrupted agrin signaling, but also complement activation.

Intriguingly, LRP4-immunized mice demonstrated presynaptic deficits: distorted axon branches, reduced overlapping areas by terminals, decreased mEPP frequency, reduce release probability, and fewer synaptic vesicles in motor nerve terminals. These deficits may be secondary to the reaction between muscle LRP4 and its antibodies, which disrupt agrin signaling pathways. Weakened postsynaptic function may subsequently cause presynaptic deficits, as observed in synapse elimination $(61,71)$. In agreement 
A

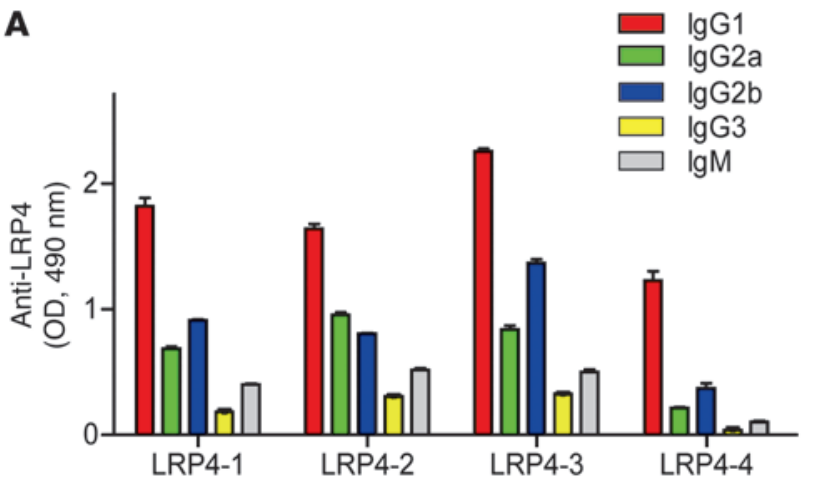

B

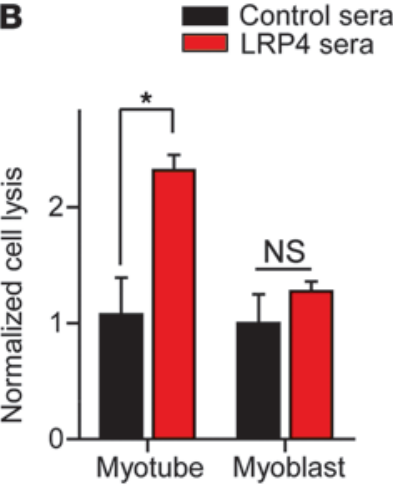

\section{Figure 8}

Complement fixation by sera of LRP4-injected mice. (A) Subclasses of anti-LRP4 antibodies. Sera from 4 LRP4-injected mice were subjected to antibody isotyping as described in Methods. (B) Increased antibodymediated cytotoxicity by sera from LRP4-injected mice. C2C12 myoblasts and myotubes were treated with heatinactivated sera from control or LRP4injected mice and guinea pig complement for 30 minutes. LDH activity was measured as described in Methods. Values were normalized to control sera (assigned as 1). Each sample was assayed in triplicate. ${ }^{*} P<0.05$. with these reports, presynaptic deficits were observed in EAMG models of AChR and MuSK, proteins that are expressed specifically in skeletal muscles $(9,40,72)$. Moreover, antibody interaction with muscle LRP4 may stimulate immune responses such as complement activation, which could damage nearby presynaptic terminals. LRP4 appears to be a ubiquitous protein and present in various tissues, including bone, mammary gland, and brain, as well as skeletal muscles and motor neurons $(24,45,57,60,73)$. However, LRP4 knockout in motor neurons did not relieve the muscle weakness, CMAP reduction in response to repeated stimulation, and impairment in presynaptic vesicle release that were caused by LRP4 immunization (Supplemental Figure 3). These results suggest that presynaptic deficits may not be caused by an immune reaction to LRP4 or by blockage of its potential function in motor neurons. This may be because of low LRP4 expression in motor neurons, which contribute $20 \%$ of LRP4 at the NMJ (57). Alternatively, posttranslational modification of LRP4 may be unique in skeletal muscles, and muscle LRP4 may therefore serve as a more pathogenic antigen in LRP4 antibody-mediated MG.

Our identification of anti-LRP4 antibodies indicates that MG is likely to be a complex disease entity, which can be classified into different subtypes with different etiologies. However, little is known about how LRP4 autoantibodies are induced in MG patients. LRP4 bears a large extracellular domain, more than twice the length of MuSK's counterpart. Abnormal posttranslational processing of the enormous extracellular region may render LRP4 an antigen. LRP4 antibody generation could be secondary to pathological processes such as inflammation, which could damage cells including muscle fibers and motor neurons and thus expose LRP4 as an antigen. In agreement, LRP4 autoantibodies were previously detected in 2 of 16 patients with neuromyelitis optica (NMO), although these patients did not exhibit MG symptoms (48). On the other hand, anti-LRP4 antibody may be induced by microbial or other exogenous antigens due to molecular mimicry. Alternatively, the large extracellular region may cross-react with antibodies against DNA or ribosomal P autoantibodies. Recently, human leukocyte antigen (HLA) haplotype and allele have been associated with early-onset MG with thymic hyperplasia (74) and anti-MuSK MG (75). However, whether these genetic variations are associated with anti-LRP4 MG remains unknown. It is worth pointing out that the prevalence of anti-LRP4 antibodies in prior studies ranges from low as $2 \%$ to as high as $50 \%$ of double-seronegative MG patients. The discrepancy may be due to geographic or ethnic differences, limited numbers of MG patients included in the studies, and/or variation in inclusion criteria. This calls for future systematic characterization of large cohorts of MG patients.

\section{Methods}

Preparation of ecto-LRP4. Ecto-LRP4 protein was produced as described previously (48). Flag-ecto-LRP4-His plasmid encoding extracellular rat LRP4 domain was generated by inserting a His tag between SalI and EcoRV sites in the pFlag-ecto-LRP4-CMV vector (57). Rat ecto-LRP4 shows $97 \%$ amino acid identity to its human homolog and can be recognized by human anti-LRP4 antibodies from MG patients (48). HEK293 cells were transfected with pFlag-ecto-LRP4-His-CMV with polyethylenimine (21). After 48 hours, transfected HEK293 cells in each $10-\mathrm{cm}$ dish were lysed in $1 \mathrm{ml}$ buffer (50 mM Tris- $\mathrm{HCl}, \mathrm{pH} 7.4 ; 150 \mathrm{mM} \mathrm{NaCl}$; $1 \%$ NP-40; $0.5 \%$ Triton-X-100; 1 mM PMSF; and protease inhibitors). After centrifuging at $16,000 \mathrm{~g}$ for 15 minutes at $4{ }^{\circ} \mathrm{C}$, cell supernatant was transferred to mix with $2 \mathrm{ml}$ TALON Metal Affinity Resins (Clontech), which was pre-equilibrated in $20 \mathrm{mM}$ MES Buffer ( $\mathrm{pH}$ 5.0) containing $300 \mathrm{mM} \mathrm{NaCl}$. The mixture was incubated overnight at $4^{\circ} \mathrm{C}$ on a rotator. After centrifuging at $700 \mathrm{~g}$ for 3 minutes at $4^{\circ} \mathrm{C}$, pellet was subjected to 315 -minute washes with 10 -bed volumes of washing buffer $(50 \mathrm{mM}$ sodium phosphate, $300 \mathrm{mM} \mathrm{NaCl}$ ). Ecto-LRP4 was eluted from the beads into fractions ( $1 \mathrm{ml}$ each) by elution buffer $(50 \mathrm{mM}$ sodium phosphate, $300 \mathrm{mM} \mathrm{NaCl}, 150 \mathrm{mM}$ imidazole) at room temperature for 15 minutes. After centrifuging at $700 \mathrm{~g}$ for 3 minutes at $4{ }^{\circ} \mathrm{C}$, supernatant was transferred to a new tube as eluted protein. The elution cycle was repeated 4 times, after which all fractions of supernatant were pooled together and dialyzed against PBS buffer at $4{ }^{\circ} \mathrm{C}$ overnight. Ecto-LRP4 was further concentrated through a centri-YM50 column (Millipore). Protein was quantified by Bradford assay. The purity of ecto-LRP4 was analyzed by silver staining with SilverXpress Silver Staining Kit (Invitrogen) and confirmed by Western blot with anti-Flag antibody (Sigma-Aldrich).

Immunization of $A / J$ mice and rabbits. Animals were housed in a room with a 12-hour light/12-hour dark cycle, with access to food and water ad libitum. Ecto-LRP4 ( $25 \mu \mathrm{g}$ in $50 \mu \mathrm{l}$ PBS) was emulsified with $50 \mu \mathrm{l}$ CFA. CFA contains $1 \mathrm{mg}$ heat-killed and dried Mycobacterium tuberculosis, $0.85 \mathrm{ml}$ paraffin oil, and $0.15 \mathrm{ml}$ mannide monooleate per milliliter. CFA-emulsified ecto-LRP4 was injected subcutaneously into 8-weekold female A/J mice (Jackson Lab) at 3 locations laterally on the back ( $\sim 33 \mu \mathrm{l} /$ injection). Female A/J mice were chosen because they have been used successfully to generate various EAMG models $(33,36)$. Control mice were injected with an emulsified mixture of PBS and CFA (50 $\mu$ l each) at 3 different locations laterally on the back ( $33 \mu \mathrm{l} /$ injection). 
A

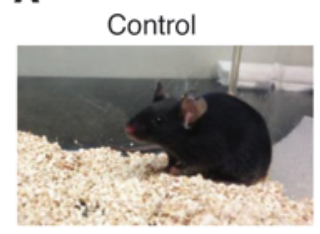

D
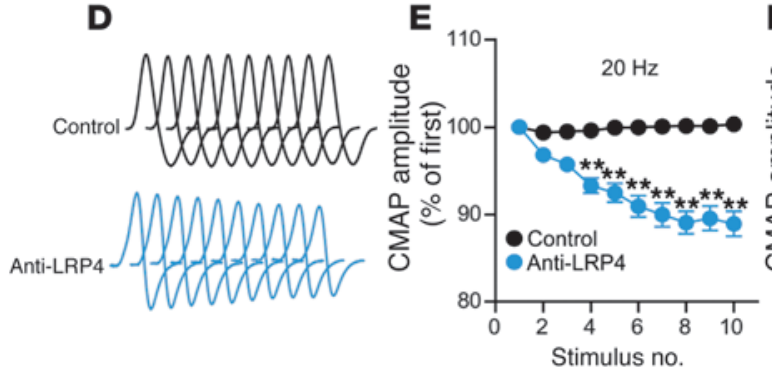

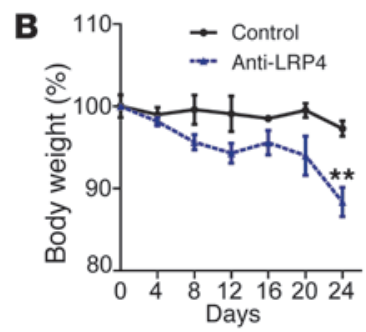

F

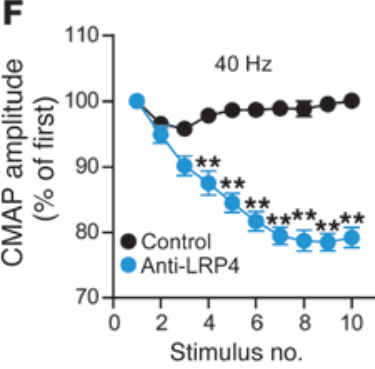

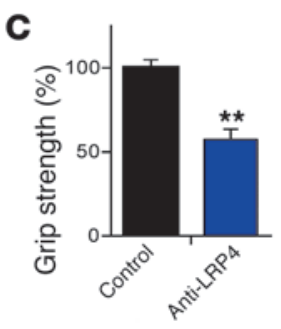

G

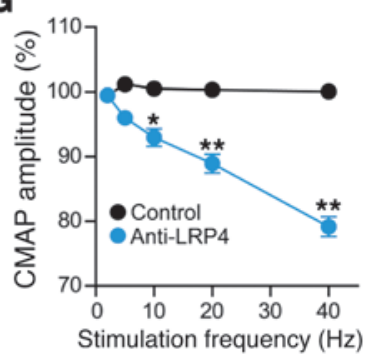

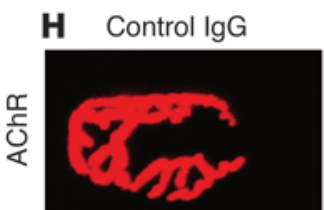
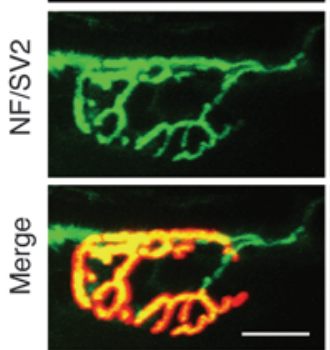

Anti-LRP4-1
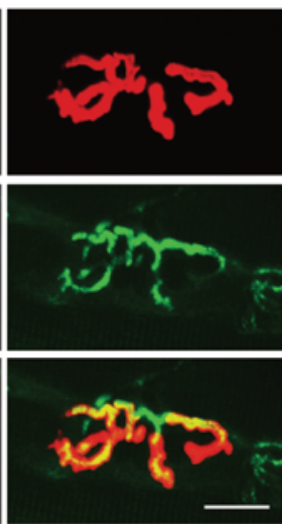

Anti-LRP4-2
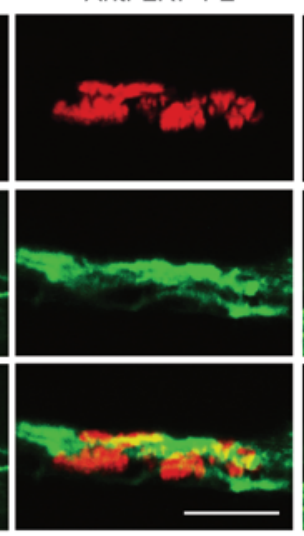

Anti-LRP4-3
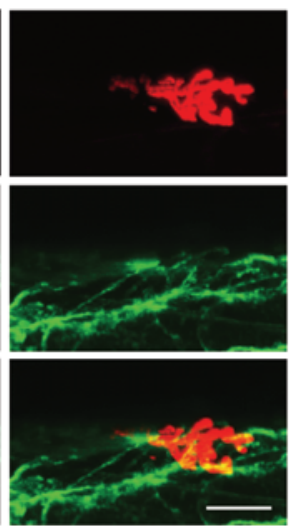

I
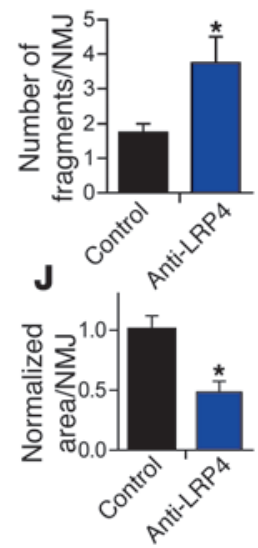

\section{Figure 9}

Induction of muscle weakness and NMJ impairment by passive transfer of anti-LRP4 IgGs. IgGs were purified from control and LRP4-immunized rabbits and injected into B6/D2 mice. (A) Representative images of mice after exercise. (B) Body weight loss in anti-LRP4 IgG-injected mice. (C) Decreased muscle strength in anti-LRP4 IgG-injected mice. (D-G) Reduced CMAPs in anti-LRP4 IgG-injected mice. (D) Representative CMAP traces. (E) CMAPs at $20 \mathrm{~Hz}$. (F) CMAPs at $40 \mathrm{~Hz}$. (G) Reduced CMAP amplitude reduction of the tenth stimulation at different frequencies. (H) Disrupted NMJs in anti-LRP4 IgG-injected mice. Shown are collapsed z-stack NMJ images. Scale bars: $20 \mu \mathrm{m}$. (I and J) Quantitative analysis of data in H. $n=3$ (control); 4 (anti-LRP4). ${ }^{*} P<0.05$; ${ }^{* \star} P<0.01$.

The time of initial immunization was designated as day 0 . At weeks 4 , 7 , and 16, mice were given boost injections with a 100- $\mu$ l mixture of IFA and ecto-LRP4 (25 $\mu \mathrm{g})$. Rabbits were immunized with CFA-emulsified ecto-LRP4 $(500 \mu \mathrm{g})$ by subcutaneous injection at different locations on the back. They were boosted at days 28,42 , and 56 , each with IFA-emulsified ecto-LRP4 $(250 \mu \mathrm{g})$.

Measurement of muscle strength and weakness. Forelimb muscle strength was determined using an SR-1 hanging scale (American Weigh Scales Inc.), as described previously (76). Mice were held by the tail, allowed to grip a grid connected to the scale, and then gently pulled horizontally until the grip was released. Muscle weakness of LRP4-injected mice was graded as described previously (54): grade 0 , no weakness after exercise test consisting of 20 consecutive paw grips on cage-top steel grids; grade 1 (moderately decreased activity), mild muscle fatigue after the exercise test; grade 2 (markedly decreased activity), hunched posture at rest; grade 3 (severe, generalized weakness), weight loss and inability to ambulate.
Unless otherwise indicated, the LRP4-injected mice examined in the present study had grade 3 muscle weakness.

Serum collection, antibody detection, and isotyping. Blood was collected from mice via orbital sinus and from rabbits via auricular vein. After 24 hours at $4{ }^{\circ} \mathrm{C}$, blood was centrifuged at 2,500 $\mathrm{g}$ for 5 minutes, and the supernatant was collected as serum. ELISA was performed as described previously (48). Maxi-Sorp Immuno 96-well plates (Nunc) were coated with $50 \mu \mathrm{l}$ of $1 \mu \mathrm{g} / \mathrm{ml}$ ecto-LRP4 in the coating buffer containing $50 \mathrm{mM}$ carbonate ( $\mathrm{pH}$ 9.6) at $4^{\circ} \mathrm{C}$ overnight, washed 6 times with TBST $(0.1 \%$ Tween- 20 in $50 \mathrm{mM}$ Tris, $150 \mathrm{mM} \mathrm{NaCl}, \mathrm{pH}$ 7.6), and incubated with the blocking buffer containing $5 \%$ nonfat milk in TBST to block nonspecific binding. Sera in different dilutions $(1: 10-1: 10,000)$ in the blocking buffer $(50 \mu$ l per well $)$ was incubated for 2 hours at $37^{\circ} \mathrm{C}$. After washing 6 times with TBST, wells were incubated with HRP-conjugated goat anti-mouse or HRP-conjugated goat anti-rabbit secondary antibody (diluted $1: 1,000$ in TBST) at $37^{\circ} \mathrm{C}$ for 1 hour. Activity of immobilized HRP was measured by OD at $490 \mathrm{~nm}$ after 
incubation with $0.4 \mathrm{mg} / \mathrm{ml}$ each of O-phenylenediamine dihydrochloride and urea hydrogen peroxide (in $0.05 \mathrm{M}$ phosphate-citrate, $\mathrm{pH}$ 5.0) at room temperature for 10 minutes. Each sample was assayed in triplicate.

LRP4 antibody subclass was determined according to the manufacturer's instructions (Sigma-Aldrich). Briefly, ecto-LRP4 was coated onto MaxiSorp Immuno 96 -well plates at $4{ }^{\circ} \mathrm{C}$ overnight. The wells were coated with $100 \mu \mathrm{l}$ blocking buffer containing sera (diluted 1:100) of LRP4-injected or control animals at $37^{\circ} \mathrm{C}$ for 1 hour, then washed 6 times with TBST buffer. Wells were then incubated with $100 \mu \mathrm{l}$ TBST buffer containing goat antimouse IgG1, IgG2a, IgG2b, IgG3, and IgM antibodies (diluted 1:1,000; Sigma-Aldrich) for 1 hour. The plates were washed 6 times with TBST buffer and incubated with HRP-conjugated rabbit anti-goat antibody (Pierce) in TBST buffer at $37^{\circ} \mathrm{C}$ for 1 hour. Activity of immobilized HRP was measured as described above. All samples were assayed in triplicate.

Analysis of MuSK activation and Western blot. C2C12 myotubes were pretreated with sera (diluted 1:100) for 3 hours, followed by stimulation with $1 \mathrm{nM}$ agrin for 30 minutes. Analysis of phospho-MuSK was performed as described previously $(21,77)$. Cells were lysed in modified RIPA buffer (50 mM Tris-HCl, pH 7.4; 150 mM NaCl; 1\% NP-40; 0.5\% Triton-X-100; $1 \mathrm{mM}$ PMSF; $1 \mathrm{mM}$ EDTA; $5 \mathrm{mM}$ sodium fluoride; $2 \mathrm{mM}$ sodium orthovanadate; and protease inhibitors). The resulting lysates (500 $\mu \mathrm{g}$ protein) were precleared by adding $30 \mu \mathrm{l}$ protein $\mathrm{A}$ for 1 hour at $4^{\circ} \mathrm{C}$ on a rotator. After centrifuging at $2,500 \mathrm{~g}$ for 5 minutes at $4{ }^{\circ} \mathrm{C}$, the supernatant was incubated with $2 \mu \mathrm{l}$ anti-MuSK antibody (57) in $1 \mathrm{ml}$ lysis buffer at $4^{\circ} \mathrm{C}$ overnight, then with $50 \mu \mathrm{l}$ protein A beads (Roche) for an additional 3 hours. Beads were washed 4 times with lysis buffer and resuspended in SDS sample buffer. Western blot analysis was performed as described previously (21). Bead-associated MuSK, purified LRP4, and cell lysates were resolved by SDS-PAGE and transferred to nitrocellulose membrane. The membrane was incubated in $2 \%$ nonfat milk in TBST buffer with the following primary antibodies for Western blot: 4G10 (anti-phospho-tyrosine; 1:1,000; 05-1050; Millipore); anti-MuSK (1:1,000; ref. 21); anti- $\alpha$-tubulin (1:2,000; sc-23948; Santa Cruz); anti-AChR (rat mAb35; 1:1,000; gift from R. Rotundo, University of Miami, Miami, Florida, USA; ref. 57); anti-Flag (1:1,000; F7425; Sigma-Aldrich), anti-LRP4 (ECD) (1:1,000; clone N207/27; UC Davis/NIH NeuroMab Facility). HRP-conjugated goat anti-mouse and rabbit/rat IgG were from Pierce (1:5,000; PI-31430, PI-31460, PI-31470). Immunoreactive bands were visualized using enhanced chemiluminescence (Pierce). Autoradiographic films were scanned with an Epson 1680 scanner, and captured images were analyzed with Image J.

Light microscopic analysis of AChR clusters. Whole-mount staining of muscles was performed as described previously (78). Gastrocnemius muscles were fixed in 4\% PFA for 1 hour and permeabilized for 2 hours with $0.5 \%$ Triton $\mathrm{X}-100$. Muscles were teased into fibers, which were incubated at $4{ }^{\circ} \mathrm{C}$ overnight with a mixture of R-BTX (1:2,000; Invitrogen) and antibodies against NF (1:1,000; AB1991; Millipore) and SV2 (1:500; Developmental Studies Hybridoma Bank). After washing with PBS 3 times, muscle fibers were incubated with goat anti-mouse/rabbit IgG conjugated with Alexa Fluor 488 (1:750; A-11029, A-11034; Invitrogen) for 2 hours at room temperature. Images were obtained with a Zeiss confocal microscope.

NMJ electron microscopy analysis. Electron microscopy was performed as described previously (79). Diaphragm muscles were fixed in $2 \%$ glutaraldehyde and $2 \%$ PFA in $0.1 \mathrm{M}$ PBS for 1 hour at $25^{\circ} \mathrm{C}$ and further fixed in $1 \%$ osmium tetroxide in sodium cacodylate buffer $(\mathrm{pH} 7.3)$ for 1 hour at $25^{\circ} \mathrm{C}$. After washing 3 times with PBS, tissues were dehydrated through a series of ethanol $(30 \%, 50 \%, 70 \%, 80 \%, 90 \%$, and $100 \%)$. After 3 rinses with $100 \%$ propylene oxide, samples were embedded in plastic resin (EM-bed 812; EMSciences). Serial thick sections (1-2 $\mu \mathrm{m})$ of tissue blocks were stained with $1 \%$ toluidine blue, then cut into ultrathin sections, mounted on 200-mesh unsupported copper grids, and stained with uranyl acetate (3\% in 50\% methanol) and lead citrate $(2.6 \%$ lead nitrate and $3.5 \%$ sodium citrate, $\mathrm{pH} 12.0$ ). Electron micrographs were taken using a JEOL 100CXII operated at $80 \mathrm{KeV}$.

Electromyography and electrophysiological recording. Mice were anesthetized with a ketamine and xylazine cocktail ( 80 and $20 \mathrm{mg} / \mathrm{kg}$ body weight, respectively). The stimulation needle electrode (TECA; 092-DMF25-S) was inserted near the sciatic nerve in left leg thigh. The reference needle electrode was inserted near the Achilles tendon, and the recording needle electrode was inserted into the middle of the gastrocnemius muscle of the left leg (40). The reference and recording electrodes were connected to an Axopatch 200B amplifier (Molecular Devices). Supramaximal stimulation was applied to the sciatic nerve with trains of 10 stimuli at 2, 5, 10, 20, and $40 \mathrm{~Hz}$ (with a 30-second pause between trains). CMAPs were collected with Digidata 1322A (Molecular Devices). Peak-to-peak amplitudes were analyzed in Clampfit 9.2 (Molecular Devices). During the experiment, mice were maintained at $37^{\circ} \mathrm{C}$ on a heating pad. After CMAP recording, mice were sacrificed and subjected to MEPP, EPP, and PPF analysis.

For analysis of neuromuscular transmission, mouse left hemidiaphragms with ribs and phrenic nerve distal endings were dissected and then pinned on Sylgard gel in oxygenated $\left(95 \% \mathrm{O}_{2}, 5 \% \mathrm{CO}_{2}\right), 26^{\circ} \mathrm{C}-28^{\circ} \mathrm{C}$ Ringer's solution ( $136.8 \mathrm{mM} \mathrm{NaCl}, 5 \mathrm{mM} \mathrm{KCl}, 12 \mathrm{mM} \mathrm{NaHCO}_{3}, 1 \mathrm{mM}$ $\mathrm{NaH}_{2} \mathrm{PO}_{4}, 1 \mathrm{mM} \mathrm{MgCl}_{2}, 2 \mathrm{mM} \mathrm{CaCl}_{2}, 11 \mathrm{mM}$ D-glucose, $\mathrm{pH}$ 7.3). Microelectrodes (20-40 M $\Omega$ when filled with $3 \mathrm{M} \mathrm{KCl}$ ) were pierced into the center of muscle fibers (40). Resting membrane potentials remained stable throughout the experiment at approximately -65 to $-75 \mathrm{mV}$. From each hemidiaphragm, $\geq 5$ muscle fibers were recorded for a $>3$-minute period. To record EPP and PPF, the phrenic nerve was held with sucking and stimulated by a platinum electrode. Trigger signals (1-ms duration) were programmed in Clampex 9.2 (Molecular Devices) and elicited from a Digidata 1322A digital output channel to stimulus isolator (AMPI; ISO-Flex). Stimulation intensity was kept at about $130 \%$ or more of the action potential threshold. Muscle contraction was blocked by $2.5 \mathrm{mM} \mu$-conotoxin GIIIB (Bachem Americas) when phrenic nerves were stimulated. Data were collected with an Axopatch 200B amplifier, digitized (10-kHz low-pass filtered) with Digidata 1322A, and analyzed in Clampfit 9.2.

Effects of mouse sera on AChR clustering. AChR clusters were assayed as previously described (77), with minor modifications. C2C12 myotubes were treated with neural agrin $(1 \mathrm{nM})$ together with mouse sera (diluted 1:100) for 16 hours, fixed in 4\% PFA, and incubated with R-BTX (diluted 1:2,000) to label AChR clusters. Myotubes were viewed using a Zeiss fluorescence microscope, and $A C h R$ clusters with diameter or axis $\geq 4 \mu \mathrm{m}$ were scored. At least 10 views per dish and at least 2 dishes were scored in each of 3 independent experiments.

Analysis of surface LRP4. C2C12 myotubes in 10-cm dishes were treated with mouse sera (diluted $1: 100$ ) at $37^{\circ} \mathrm{C}$ for 1 hour. Biotin-labeled cell surface protein was analyzed as previously described (80). Cells were washed 3 times with ice-cold PBS containing $1 \mathrm{mM} \mathrm{MgCl}_{2}$ and $0.1 \mathrm{mM} \mathrm{CaCl}_{2}$, then incubated with $0.5 \mathrm{mg} / \mathrm{ml}$ Sulfo-NHS-LC-Biotin (Sigma-Aldrich) at room temperature for 30 minutes. After washing once with ice-cold PBS containing $1 \mathrm{mM} \mathrm{MgCl}_{2}$ and $0.1 \mathrm{mM} \mathrm{CaCl}_{2}$, cells were incubated with $0.1 \mathrm{M}$ glycine to quench the biotin reaction. Cells were washed 3 times in icecold PBS, harvested in modified RIPA buffer, and centrifuged at $21,000 \mathrm{~g}$ for 15 minutes at $4^{\circ} \mathrm{C}$. The supernatant was incubated with $50 \mu \mathrm{l}$ of $50 \%$ avidin agarose (Thermo) overnight at $4^{\circ} \mathrm{C}$ on a rotator. Beads were washed 5 times with modified RIPA buffer, and bound proteins were eluted with $40 \mu \mathrm{l}$ SDS sample buffer. Lysates and biotinylated surface proteins were subjected to Western blot for LRP4 as described above.

Complement fixation assay. C2C12 myoblasts and myotubes were incubated with mouse sera (diluted 1:100) for 30 minutes at $37^{\circ} \mathrm{C}$. After the 
addition of guinea pig complement (diluted 1:200; Sigma-Aldrich), cells were incubated for 60 minutes at $37^{\circ} \mathrm{C}$. LDH in conditioned medium was assessed using a LDH cytotoxicity detection kit according to the manufacturer's instructions (Promega). As a control, LDH was also measured in conditioned medium of cells without treatment, to reveal spontaneous release, and cells that were lysed by lysis buffer, to reveal maximal LDH release. LDH released by mouse sera-treated cells was calculated as (LDH released by sera-treated cells - spontaneous LDH release)/(maximal LDH release - spontaneous LDH release) and expressed as a percentage. The value of control sera was normalized as 1 .

Passive EAMG model. Rabbit IgG was purified as previously described (67). Briefly, 4.2 M saturated ammonium sulfate (SAS) was slowly added to rabbit sera to $45 \%(\mathrm{v} / \mathrm{v})$ with mild vortexing. After overnight incubation at $4{ }^{\circ} \mathrm{C}$, the mixture was centrifuged for 1 hour at $20,000 \mathrm{~g}$ at $4^{\circ} \mathrm{C}$. Precipitate was dissolved in PBS, dialyzed against $50 \mathrm{~V}$ cold PBS for 24 hours at $4^{\circ} \mathrm{C}$, and concentrated to $2 \mathrm{ml}$ using a centri-YM30 column (Millipore). To purify rabbit IgG, the sample was subjected to chromatography on a Sephacryl S-200 superfine column (GE Healthcare). The purity of rabbit IgG in fractions was analyzed by nondenaturing and denaturing PAGE. Purified rabbit IgG was concentrated to $>50 \mathrm{mg} / \mathrm{ml}$ by a centri-YM30 column and injected into mice as previously described (68). Briefly, 8-week-old female B6/D2 F1 mice (Jackson Lab) were injected i.p. with $10 \mathrm{mg}$ rabbit IgG in $200 \mu \mathrm{l}$ sterile PBS every day for 24 days. Mice were given a single i.p. injection of cyclophosphamide monohydrate ( $300 \mathrm{mg} / \mathrm{kg}$; Sigma-Aldrich)
24 hours after the first IgG injection to suppress a potential immune reaction against rabbit IgG. Characterization of these mice was similar to the active EAMG models described above.

Statistics. Data were analyzed by 2-tailed paired or unpaired Student's $t$ test. Unless otherwise indicated, data were expressed as mean \pm SEM. A $P$ value less than 0.05 was considered significant.

Study approval. All animal experiments were approved by the Institutional Animal Care and Use Committee of Georgia Regents University.

\section{Acknowledgments}

We are grateful to the Georgia Regents University histology core laboratory for electron microscopic analysis, Richard Rotundo for mAb35, and Jianhua Xu and members of the Mei and Xiong laboratories for discussions. This work was supported in part by grants from Muscular Dystrophy Association (MDA240849) and National Institutes of Health. L. Mei is a GRA Eminent Scholar in Neuroscience.

Received for publication July 10, 2013, and accepted in revised form August 29, 2013.

Address correspondence to: Lin Mei, 1120, 15th street, Georgia Regents University, Augusta, Georgia 30912, USA. Phone: 706.721.8775; Fax: 706.721.8685; E-mail: lmei@gru.edu.
1. Vincent A. Unravelling the pathogenesis of myasthenia gravis. Nat Rev Immunol. 2002;2(10):797-804.

2. Carr AS, Cardwell CR, McCarron PO, McConville J. A systematic review of population based epidemiological studies in Myasthenia Gravis. BMC Neurol. 2010;10:46.

3. Phillips LH 2nd. The epidemiology of myasthenia gravis. Ann N Y Acad Sci. 2003;998:407-412.

4. Vincent A, Newsom-Davis J. Acetylcholine receptor antibody as a diagnostic test for myasthenia gravis: results in 153 validated cases and 2967 diagnostic assays. J Neurol Neurosurg Psychiatry. 1985; 48(12):1246-1252.

5. Lindstrom JM, Seybold ME, Lennon VA, Whittingham S, Duane DD. Antibody to acetylcholine receptor in myasthenia gravis. Prevalence, clinical correlates, and diagnostic value. Neurology. 1976; 26(11):1054-1059.

6. Patrick J, Lindstrom J. Autoimmune response to acetylcholine receptor. Science. 1973; 180(4088):871-872.

7. Kao I, Drachman DB. Myasthenic immunoglobulin accelerates acetylcholine receptor degradation. Science. 1977;196(4289):527-529.

8. Bevan S, Heinemann S, Lennon VA, Lindstrom J. Reduced muscle acetylcholine sensitivity in rats immunised with acetylcholine receptor. Nature. 1976; 260(5550):438-439.

9. Lambert EH, Lindstrom JM, Lennon VA. End-plate potentials in experimental autoimmune myasthenia gravis in rats. Ann N Y Acad Sci. 1976;274:300-318.

10. Toyka KV, et al. Myasthenia gravis. Study of humoral immune mechanisms by passive transfer to mice. N Engl J Med. 1977;296(3):125-131.

11. Green DP, Miledi R, Vincent A. Neuromuscular transmission after immunization against acetylcholine receptors. Proc R Soc Lond B Biol Sci. 1975; 189(1094):57-68

12. Engel AG, Tsujihata M, Lindstrom JM, Lennon VA. The motor end plate in myasthenia gravis and in experimental autoimmune myasthenia gravis. A quantitative ultrastructural study. Ann N Y Acad Sci. 1976;274:60-79.

13. Lennon VA, Lindstrom JM, Seybold ME. Experimental autoimmune myasthenia: A model of myasthenia gravis in rats and guinea pigs. J Exp
Med. 1975;141(6):1365-1375.

14. Lennon VA, Lambert EH. Myasthenia gravis induced by monoclonal antibodies to acetylcholine receptors. Nature. 1980;285(5762):238-240.

15. Richman DP, Gomez CM, Berman PW, Burres SA, Fitch FW, Arnason BG. Monoclonal anti-acetylcholine receptor antibodies can cause experimental myasthenia. Nature. 1980;286(5774):738-739.

16. Aharonov A, Tarrab-Hazdai R, Abramsky O, Fuchs $\mathrm{S}$. Immunological relationship between acetylcholine receptor and thymus: a possible significance in myasthenia gravis. Proc Natl Acad Sci U S A. 1975;72(4):1456-1459.

17. Engel AG, Arahata K. The membrane attack complex of complement at the endplate in myasthenia gravis. Ann N Y Acad Sci. 1987;505:326-332.

18. Engel AG, Lambert EH, Howard FM. Immune complexes (IgG and C3) at the motor end-plate in myasthenia gravis: ultrastructural and light microscopic localization and electrophysiologic correlations. Mayo Clin Proc. 1977;52(5):267-280.

19. McMahan UJ. The agrin hypothesis. Cold Spring Harb Symp Quant Biol. 1990;55:407-418.

20. Kim N, et al. Lrp4 is a receptor for Agrin and forms a complex with MuSK. Cell. 2008;135(2):334-342.

21. Zhang B, Luo S, Wang Q, Suzuki T, Xiong WC, Mei L. LRP4 serves as a coreceptor of agrin. Neuron. 2008; 60(2):285-297.

22. Wu H, Xiong WC, Mei L. To build a synapse: signaling pathways in neuromuscular junction assembly. Development. 2010;137(7):1017-1033.

23. Misgeld T, Kummer TT, Lichtman JW, Sanes JR. Agrin promotes synaptic differentiation by counteracting an inhibitory effect of neurotransmitter. Proc Natl Acad Sci U S A. 2005;102(31):11088-11093.

24. Weatherbee SD, Anderson KV, Niswander LA. LDL-receptor-related protein 4 is crucial for formation of the neuromuscular junction. Development. 2006;133(24):4993-5000.

25. Zong Y, et al. Structural basis of agrin-LRP4-MuSK signaling. Genes Dev. 2012;26(3):247-258.

26. DeChiara TM, et al. The receptor tyrosine kinase MuSK is required for neuromuscular junction formation in vivo. Cell. 1996;85(4):501-512.

27. Glass DJ, et al. Agrin acts via a MuSK receptor complex. Cell. 1996;85(4):513-523.
28. Hoch W, McConville J, Helms S, Newsom-Davis J, Melms A, Vincent A. Auto-antibodies to the receptor tyrosine kinase MuSK in patients with myasthenia gravis without acetylcholine receptor antibodies. Nat Med. 2001;7(3):365-368.

29. Sanders DB, El-Salem K, Massey JM, McConville J, Vincent A. Clinical aspects of MuSK antibody positive seronegative MG. Neurology. 2003; 60(12):1978-1980.

30. McConville J, et al. Detection and characterization of MuSK antibodies in seronegative myasthenia gravis. Ann Neurol. 2004;55(4):580-584.

31. Shigemoto K, et al. Induction of myasthenia by immunization against muscle-specific kinase. J Clin Invest. 2006;116(4):1016-1024.

32. Shigemoto K, et al. Myasthenia gravis experimentally induced with muscle-specific kinase. Ann NY Acad Sci. 2008;1132:93-98.

33. Jha S, et al. Myasthenia gravis induced in mice by immunization with the recombinant extracellular domain of rat muscle-specific kinase (MuSK). J Neuroimmunol. 2006;175(1-2):107-117.

34. Xu K, Jha S, Hoch W, Dryer SE. Delayed synapsing muscles are more severely affected in an experimental model of MuSK-induced myasthenia gravis. Neuroscience. 2006;143(3):655-659.

35. Punga AR, Lin S, Oliveri F, Meinen S, Rüegg MA. Muscle-selective synaptic disassembly and reorganization in MuSK antibody positive MG mice. Exp Neurol. 2011;230(2):207-217.

36. Mori S, et al. Antibodies against muscle-specific kinase impair both presynaptic and postsynaptic functions in a murine model of myasthenia gravis. Am J Pathol. 2012;180(2):798-810.

37. Cole RN, Reddel SW, Gervásio OL, Phillips WD. Anti-MuSK patient antibodies disrupt the mouse neuromuscular junction. Ann Neurol. 2008; 63(6):782-789.

38. Cole RN, Ghazanfari N, Ngo ST, Gervásio OL, Reddel SW, Phillips WD. Patient autoantibodies deplete postsynaptic muscle-specific kinase leading to disassembly of the ACh receptor scaffold and myasthenia gravis in mice. J Physiol. 2010; 588(pt 17):3217-3229.

39. ter Beek WP, et al. The effect of plasma from muscle-specific tyrosine kinase myasthenia patients 
on regenerating endplates. Am J Pathol. 2009; 175(4):1536-1544.

40. Klooster R, et al. Muscle-specific kinase myasthenia gravis IgG4 autoantibodies cause severe neuromuscular junction dysfunction in mice. Brain. 2012; 135(pt 4):1081-1101.

41. Richman DP, et al. Acute severe animal model of antimuscle-specific kinase myasthenia: combined postsynaptic and presynaptic changes. Arch Neurol. 2012; 69(4):453-460.

42. Lu Y, Tian QB, Endo S, Suzuki T. A role for LRP4 in neuronal cell viability is related to apoE-binding. Brain Res. 2007;1177:19-28.

43. Johnson EB, Hammer RE, Herz J. Abnormal development of the apical ectodermal ridge and polysyndactyly in Megf7-deficient mice. Hum Mol Genet. 2005; 14(22):3523-3538.

44. Yamaguchi YL, Tanaka SS, Kasa M, Yasuda K, Tam PP, Matsui Y. Expression of low density lipoprotein receptor-related protein 4 (Lrp4) gene in the mouse germ cells. Gene Expr Patterns. 2006;6(6):607-612.

45. Tian QB, et al. Interaction of LDL receptor-related protein 4 (LRP4) with postsynaptic scaffold proteins via its C-terminal PDZ domain-binding motif, and its regulation by $\mathrm{Ca} / \mathrm{calmodulin}$-dependent protein kinase II. Eur J Neurosci. 2006;23(11):2864-2876.

46. Zong Y, et al. Structural basis of agrin-LRP4-MuSK signaling. Genes Dev. 2012;26(3):247-258.

47. Pevzner A, et al. Anti-LRP4 autoantibodies in AChR- and MuSK-antibody-negative myasthenia gravis. J Neurol. 2012;259(3):427-435.

48. Zhang B, et al. Autoantibodies to lipoproteinrelated protein 4 in patients with double-seronegative myasthenia gravis. Arch Neurol. 2012; 69(4):445-451.

49. Higuchi O, Hamuro J, Motomura M, Yamanashi Y. Autoantibodies to low-density lipoprotein receptorrelated protein 4 in myasthenia gravis. Ann Neurol. 2011;69(2):418-422.

50. Marx A, et al. Expression of neurofilaments and of a titin epitope in thymic epithelial tumors. Implications for the pathogenesis of myasthenia gravis. Am J Pathol. 1996;148(6):1839-1850.

51. Baggi $\mathrm{F}$, et al. Anti-titin and antiryanodine receptor antibodies in myasthenia gravis patients with thymoma. Ann N Y Acad Sci. 1998;841:538-541.

52. Yamamoto AM, et al. Anti-titin antibodies in myasthenia gravis: tight association with thymoma and heterogeneity of nonthymoma patients. Arch Neurol. 2001 58(6):885-890.

53. Giraud M, et al. Linkage of HLA to myasthenia gravis and genetic heterogeneity depending on antititin antibodies. Neurology. 2001;57(9):1555-1560.

54. Nakayashiki N, Oshima M, Deitiker PR, Ashizawa
T, Atassi MZ. Suppression of experimental myasthenia gravis by monoclonal antibodies against MHC peptide region involved in presentation of a pathogenic T-cell epitope. J Neuroimmunol. 2000; 105(2):131-144.

55. Roses AD, Olanow CW, McAdams MW, Lane RJ. No direct correlation between serum antiacetylcholine receptor antibody levels and clinical state of individual patients with myasthenia gravis. Neurology. 1981;31(2):220-224.

56. Pachner AR, Kantor FS. The relation of clinical disease to antibody titre, proliferative response and neurophysiology in murine experimental autoimmune myasthenia gravis. Clin Exp Immunol. 1983; 51(3):543-550.

57. Wu H, et al. Distinct roles of muscle and motoneuron LRP4 in neuromuscular junction formation. Neuron. 2012;75(1):94-107.

58. Tzartos SJ, Sophianos D, Zimmerman K, StarzinskiPowitz A. Antigenic modulation of human myotube acetylcholine receptor by myasthenic sera. Serum titer determines receptor internalization rate. J Immunol. 1986;136(9):3231-3238.

59. Burden SJ, Yumoto N, Zhang W. The role of MuSK in synapse formation and neuromuscular disease. Cold Spring Harb Perspect Biol. 2013;5(5):a009167.

60. Ahn Y, Sims C, Logue JM, Weatherbee SD, Krumlauf R. Lrp4 and Wise interplay controls the formation and patterning of mammary and other skin appendage placodes by modulating Wnt signaling. Development. 2013;140(3):583-593.

61. McCann CM, Nguyen QT, Santo Neto H, Lichtman JW. Rapid synapse elimination after postsynaptic protein synthesis inhibition in vivo. J Neurosci. 2007; 27(22):6064-6067.

62. Kong XC, Barzaghi P, Ruegg MA. Inhibition of synapse assembly in mammalian muscle in vivo by RNA interference. EMBO Rep. 2004;5(2):183-188.

63. Hesser BA, Henschel O, Witzemann V. Synapse disassembly and formation of new synapses in postnatal muscle upon conditional inactivation of MuSK Mol Cell Neurosci. 2006;31(3):470-480.

64. Klaus GG, Pepys MB, Kitajima K, Askonas BA. Activation of mouse complement by different classes of mouse antibody. Immunology. 1979; 38(4):687-695

65. Neuberger MS, Rajewsky K. Activation of mouse complement by monoclonal mouse antibodies. Eur J Immunol. 1981;11(12):1012-1016.

66. Zhang G, et al. Anti-ganglioside antibody-mediated neuronal cytotoxicity and its protection by intravenous immunoglobulin: implications for immune neuropathies. Brain. 2004;127(pt 5):1085-1100.

67. Grodzki AC, Berenstein E. Antibody purification: ammonium sulfate fractionation or gel filtration. Methods Mol Biol. 2010;588:15-26

68. Toyka KV, Brachman DB, Pestronk A, Kao I. Myasthenia gravis: passive transfer from man to mouse. Science. 1975;190(4212):397-399.

69. Hopf C, Hoch W. Dimerization of the musclespecific kinase induces tyrosine phosphorylation of acetylcholine receptors and their aggregation on the surface of myotubes. J Biol Chem. 1998; 273(11):6467-6473

70. Zhang W, Coldefy AS, Hubbard SR, Burden SJ. Agrin binds to the $\mathrm{N}$-terminal region of Lrp4 protein and stimulates association between Lrp4 and the first immunoglobulin-like domain in muscle-specific kinase (MuSK). J Biol Chem. 2011; 286(47):40624-40630

71. Culican SM, Nelson CC, Lichtman JW. Axon withdrawal during synapse elimination at the neuromuscular junction is accompanied by disassembly of the postsynaptic specialization and withdrawal of Schwann cell processes. J Neurosci. 1998; 18(13):4953-4965.

72. Viegas S, et al. Passive and active immunization models of MuSK-Ab positive myasthenia: electrophysiological evidence for pre and postsynaptic defects. Exp Neurol. 2012;234(2):506-512.

73. Karner CM, et al. Lrp4 regulates initiation of ureteric budding and is crucial for kidney formation - a mouse model for Cenani-Lenz syndrome. PLoS One. 2010;5(4):e10418.

74. Vandiedonck C, Giraud M, Garchon HJ. Genetics of autoimmune myasthenia gravis: the multifaceted contribution of the HLA complex. J Autoimmun. 2005; 25(suppl):6-11.

75. Niks EH, et al. Strong association of MuSK antibodypositive myasthenia gravis and HLA-DR14-DQ5. Neurology. 2006;66(11):1772-1774.

76. Buss RR, et al. Neuromuscular development in the absence of programmed cell death: phenotypic alteration of motoneurons and muscle. J Neurosci. 2006; 26(52):13413-13427.

77. Zhang B, Liang C, Bates R, Yin Y, Xiong WC, Mei L. Wnt proteins regulate acetylcholine receptor clustering in muscle cells. Mol Brain. 2012;5:7.

78. Luo S, et al. HSP90 $\beta$ regulates rapsyn turnover and subsequent AChR cluster formation and maintenance. Neuron. 2008;60(1):97-110.

79. Wu H, et al. $\beta$-Catenin gain of function in muscles impairs neuromuscular junction formation. Development. 2012;139(13):2392-2404.

80. Yang XL, Huang YZ, Xiong WC, Mei L. Neuregulin-induced expression of the acetylcholine receptor requires endocytosis of ErbB receptors. Mol Cell Neurosci. 2005;28(2):335-346 